\title{
Phylogenomics of Haloarchaea: The Controversy of the Genera Natrinema-Haloterrigena
}

\author{
Rafael R. de la Haba', Hiroaki Minegishi², Masahiro Kamekura ${ }^{3}$, Yasuhiro Shimane $^{4}$ and \\ Antonio Ventosa ${ }^{1 *}$ \\ ${ }^{1}$ Department of Microbiology and Parasitology, Faculty of Pharmacy, University of Sevilla, Sevilla, Spain, ${ }^{2}$ Department \\ of Applied Chemistry, Faculty of Science and Engineering, Toyo University, Kawagoe, Japan, ${ }^{3}$ Halophiles Research Institute, \\ Chiba, Japan, ${ }^{4}$ Japan Agency for Marine-Earth Science and Technology, Yokosuka, Japan
}

\section{OPEN ACCESS}

Edited by:

Richard Allen White III, University of North Carolina at Charlotte, United States

Reviewed by:

Munusamy Madhaiyan, Temasek Life Sciences Laboratory,

Singapore

Aharon Oren

Hebrew University of Jerusalem, Israe Heng-Lin Cui,

Jiangsu University, China

${ }^{*}$ Correspondence: Antonio Ventosa ventosa@us.es

Specialty section:

This article was submitted to Extreme Microbiology, a section of the journal

Frontiers in Microbiology

Received: 13 July 2021 Accepted: 25 August 2021 Published: 07 October 2021

Citation:

de la Haba RR, Minegishi $H$,

Kamekura M, Shimane $Y$ and Ventosa A (2021) Phylogenomics of Haloarchaea: The Controversy of the Genera Natrinema-Haloterrigena.

Front. Microbiol. 12:740909.

doi: 10.3389/fmicb.2021.740909
The haloarchaeal genera Natrinema and Haloterrigena were described almost simultaneously by two different research groups and some strains studied separately were described as different species of these genera. Furthermore, the description of additional species were assigned to either Natrinema or Haloterrigena, mainly on the basis of the phylogenetic comparative analysis of single genes (16S rRNA gene and more recently rpoB' gene), but these species were not adequately separated or assigned to the corresponding genus. Some studies suggested that the species of these two genera should be unified into a single genus, while other studies indicated that the genera should remain but some of the species should be reassigned. In this study, we have sequenced or collected the genomes of the type strains of species of Natrinema and Haloterrigena and we have carried out a comparative genomic analysis in order to clarify the controversy related to these two genera. The phylogenomic analysis based on the comparison of 525 translated single-copy orthologous genes and the Overall Genome Relatedness Indexes (i.e., AAI, POCP, ANI, and dDDH) clearly indicate that the species Haloterrigena hispanica, Haloterrigena limicola, Haloterrigena longa, Haloterrigena mahii, Haloterrigena saccharevitans, Haloterrigena thermotolerans, and Halopiger salifodinae should be transferred to the genus Natrinema, as Natrinema hispanicum, Natrinema limicola, Natrinema longum, Natrinema mahii, Natrinema saccharevitans, Natrinema thermotolerans, and Natrinema salifodinae, respectively. On the contrary, the species Haloterrigena turkmenica, Haloterrigena salifodinae, and Haloterrigena salina will remain as the only representative species of the genus Haloterrigena. Besides, the species Haloterrigena daqingensis should be reclassified as a member of the genus Natronorubrum, as Natronorubrum daqingense. At the species level, Haloterrigena jeotgali and Natrinema ejinorense should be considered as a later heterotypic synonyms of the species Haloterrigena (Natrinema) thermotolerans and Haloterrigena (Natrinema) longa, respectively. Synteny analysis and phenotypic features also supported those proposals.

Keywords: haloarchaea, Halobacteria, Natrinema, Haloterrigena, comparative genomic analysis, taxophylogenomic analysis 


\section{INTRODUCTION}

Haloarchaea are a monophyletic group of extremely halophilic archaea affiliated to the single class Halobacteria, belonging to the phylum Euryarchaeota (Oren et al., 2017). Currently, the class Halobacteria comprises three orders (i.e., Halobacteriales, Haloferacales, and Natrialbales), six families (i.e., Halobacteriaceae, Haloarculaceae, Halococcaceae, Haloferacaceae, Halorubraceae, and Natrialbaceae), 72 genera and 289 species whose names have been validly published (Parte et al., 2020), reflecting the high diversity and complex phylogenetic relationships within the haloarchaea. In fact, recent pan-genome analysis and ancestral state reconstruction has brought to light the heterogeneity of this class, which possesses an open pan-genome, and the occurrence of genome expansion and horizontal gene transfer during the evolution of Halobacteria (Gaba et al., 2020).

The genera Natrinema and Haloterrigena are members of the family Natrialbaceae. The genus Natrinema was described in October 1998 (McGenity et al., 1998), just 3 months earlier than the genus Haloterrigena (Ventosa et al., 1999). For that reason, the latter article did not include the recently described strains of Natrinema for comparative purposes since the manuscript was submitted for peer-review before the acceptance of the former. Therefore, Ventosa et al. (1999), honestly according to their results, proposed the creation of the new genus Haloterrigena with the new species Htg. turkmenica, instead of a novel species within the genus Natrinema, which would have been more advisable. Since then, several new species affiliated to both genera have been described and, nowadays, the genus Natrinema comprises eight validly published species names (Minegishi and Kamekura, 2019b) while Haloterrigena harbors 11 species (Chen et al., 2019; Minegishi and Kamekura, 2019a). In addition, other non-validated species names have been proposed, specifically, "Natrinema ajinwuensis" (Mahansaria et al., 2018) and "Natrinema thermophila" (Kim et al., 2018), as well as isolates not-yet assigned to any existent species (Natrinema sp. J7-1, Natrinema sp. J7-2, Haloterrigena sp. GSL-11, and Haloterrigena sp. SGH1) (Post and Al-Harjan, 1988; Zhang et al., 2012; Flores et al., 2020).

Several studies have pointed out the taxonomic problems arising in the genera Natrinema and Haloterrigena from the fact that molecular markers (i.e., $16 \mathrm{~S}$ rRNA, atpB, EF-2, radA, rpoB', and $\sec Y$ gene sequences) and DNA-DNA hybridization data suggest an overlapping among members of both genera (Oren and Ventosa, 2002; Tindall, 2003; Wright, 2006; Enache et al., 2007; Minegishi et al., 2010; Papke et al., 2011). However, a detailed phylogenomic and comparative genomic study based on whole genome sequences has not been accomplished yet, nor was a formal proposal made to unravel the controversy between the cluster Natrinema/Haloterrigena. Moreover, the taxonomic status of the closely related genus Natronorubrum deserves special attention because $16 \mathrm{~S}$ rRNA gene phylogenetic reconstructions suggest that the species Natronorubrum sediminis might belong to the Natrinema/Haloterrigena group, as the closest relative to Haloterrigena daqingensis (Ruiz-Romero et al., 2013). Since Natronorubrum sediminis (Gutiérrez et al., 2010) and
Haloterrigena daqingensis (Wang et al., 2010) were proposed at almost the same time (only a 2-month gap), their close relationship was not noticed at that time. Additionally, the species Halopiger salifodinae seems to be properly affiliated to the genus Halopiger according to the 16S rRNA gene-based phylogeny, but complete rpoB' gene sequence analysis (which has been demonstrated to be a more advantageous phylogenetic marker than the 16S rRNA gene in the class Halobacteria) (Minegishi et al., 2010), indicated its closest relationship with the Natrinema/Haloterrigena cluster (Minegishi et al., 2016).

In the post-genomic era, it is possible to take advantage of big genome databases and low-cost sequencing to infer phylogenetic relationships among prokaryotes using the core orthologous genes detected in the genomes under study in order to accurately elucidate their evolutionary history (de la Haba et al., 2019). Besides, comparative genomics and Overall Genome Related Indexes (OGRI) have been proposed as approaches to inspect the evolutionary distance among species and to delineate prokaryotic taxa at family, genus and species level (Borriss et al., 2011; Chun and Rainey, 2014; Konstantinidis et al., 2017; Ramírez-Durán et al., 2021) and current taxonomy should benefit from them.

Aimed to resolve the taxonomic issues in the cluster Natrinema/Haloterrigena and related taxa within the family Natrialbaceae, we conducted phylogenomic and comparative genomic analyses using available dataset from public databanks. Additionally, we also obtained the whole genome sequence of a relevant type strain of this family which was missing in data banks. Several taxonomic changes are formally proposed in view of our results.

\section{MATERIALS AND METHODS}

\section{Genome Retrieval and Sequencing}

All genome sequences from type strains of species of the family Natrialbaceae available until May 31st, 2020 in NCBI GenBank database were retrieved. Other additional genomes from reference (non-type) strains of Natrinema/Haloterrigena genera were also recovered (Table 1). Whole genome sequences were annotated following the NCBI Prokaryotic Genome Annotation Pipeline (PGAP) (Haft et al., 2018) to predict proteincoding genes as well as other functional genome units, such as structural RNAs and tRNAs.

The genome sequence of the type strain of Haloterrigena longa was not available in any searched public database (NCBI GenBank, JGI Genome Portal, Global Catalog of Type Strain). Since that sequence data was quite relevant for the present work, we obtained the type material from the Japanese Collection of Microorganisms for the aforementioned strain (JCM 13563) and further processed it in order to obtain its whole genome sequence. High-quality genomic DNA was extracted using the QIAmp DNA Mini Kit (Qiagen) following the manufacturer's instructions. Library preparation was performed using a combination of paired-end and mate pair strategies to generate short-insert and long-insert paired-end DNA libraries, respectively. DNA fragments were sequenced on an Illumina MiSeq platform to obtain $2 \times 301$-bp short-insert paired-end 
TABLE 1 | Main features of genome sequences of strains of the family Natrialbaceae used in this study.

\begin{tabular}{|c|c|c|c|c|c|c|c|c|c|c|}
\hline Strain & Accession no. & Assembly & Level & Size (Mb) & GC\% & Scaffolds & Contigs & CDS & N50 & L50 \\
\hline Halobiforma haloterrestris DSM $13078^{\top}$ & FOKW00000000.1 & GCA_900112205.1 & Scaffold & 4.50 & 65.4 & 31 & 32 & 4273 & 375,716 & 4 \\
\hline Halobiforma lacisalsi AJ5 ${ }^{\top}$ & СР019285.1 & GCA_000226975.3 & Complete & 4.38 & 65.2 & 3 & 3 & 4177 & $4,161,587$ & 1 \\
\hline Halobiforma nitratireducens JCM $10879^{\top}$ & AOMA00000000.1 & GCA_000337895.1 & Contig & 3.69 & 63.7 & 205 & 205 & 3552 & 47,406 & 25 \\
\hline Halopiger aswanensis DSM $13151^{\top}$ & RAPO00000000.1 & GCA_003610195.1 & Scaffold & 4.87 & 64.4 & 17 & 18 & 4589 & $1,426,401$ & 2 \\
\hline Halopiger djelfimassiliensis $\mathrm{IH}^{\top}$ & CBMA00000000.1 & GCA_000455365.1 & Scaffold & 3.78 & 64.2 & 6 & 55 & 3671 & $1,082,527$ & 2 \\
\hline Halopiger goleimassiliensis $\|_{H}{ }^{\top}$ & CBMB00000000.1 & GCA_000455345.1 & Scaffold & 3.91 & 66.1 & 3 & 11 & 3756 & $3,025,424$ & 1 \\
\hline Halopiger salifodinae CGMCC $1.12284^{\top}$ & FOISO0000000.1 & GCA_900110455.1 & Scaffold & 4.27 & 65.4 & 8 & 9 & 4010 & 878,349 & 3 \\
\hline Halopiger xanaduensis $\mathrm{SH}-6^{\top}$ & NC_015666.1 & GCA_000217715.1 & Complete & 4.36 & 65.2 & 4 & 4 & 4178 & $3,668,009$ & 1 \\
\hline Halostagnicola kamekurae DSM $22427^{\top}$ & FOZS00000000.1 & GCA_900116205.1 & Contig & 4.11 & 61.5 & 16 & 16 & 4042 & $1,202,185$ & 2 \\
\hline Halostagnicola larsenii $X \mathrm{H}-48^{\top}$ & СР007055.1 & GCA_000517625.1 & Complete & 4.13 & 60.9 & 5 & 5 & 3966 & $2,789,326$ & 1 \\
\hline Haloterrigena daqingensis CGMCC $1.8909^{\top}$ & FTNP00000000.1 & GCA_900156445.1 & Contig & 3.83 & 61.4 & 14 & 14 & 3687 & 859,600 & 2 \\
\hline Haloterrigena daqingensis $\mathrm{J} \times 313^{\top}$ & СР019327.1 & GCA_001971705.1 & Complete & 3.84 & 61.3 & 4 & 4 & 3692 & $3,397,437$ & 1 \\
\hline Haloterrigena hispanica CDM_1 & FMZP00000000.1 & GCA_900101245.1 & Scaffold & 3.91 & 61.0 & 135 & 139 & 3983 & 148,801 & 9 \\
\hline Haloterrigena hispanica CDM_6 & FOIC00000000.1 & GCA_900111485.1 & Scaffold & 3.96 & 61.0 & 92 & 100 & 3989 & 128,565 & 9 \\
\hline Haloterrigena hispanica DSM $18328^{\top}$ & SHMP00000000.1 & GCA_004217335.1 & Contig & 4.26 & 60.7 & 11 & 11 & 4121 & $1,073,359$ & 2 \\
\hline Haloterrigena jeotgali $\mathrm{A}_{2} \mathrm{~T}^{\top}$ & CP031303.1 (chromosome), & GCA_004799625.1 & Complete & 4.90 & 65.0 & 7 & 7 & 4967 & $3,644,881$ & 1 \\
\hline
\end{tabular}

Haloterrigena limicola JCM $13563^{\top}$ Haloterrigena longa JCM $13563^{\top}$ Haloterrigena mahii $\mathrm{H}_{1} 3^{\top}$

Haloterrigena saccharevitans $\mathrm{AB} 14^{\top}$ Haloterrigena salifodinae $\mathrm{ZY} 19^{\top}$

Haloterrigena salina JCM $13891^{\top}$

Haloterrigena sp. $\mathrm{H} 1$

Haloterrigena thermotolerans DSM $11552^{\top}$

Haloterrigena turkmenica DSM $5511^{\top}$

Haloterrigena turkmenica WANU15

Halovivax asiaticus JCM $14624^{\top}$

Halovivax ruber $\mathrm{XH}-70^{\top}$

Natrarchaeobaculum aegyptiacum JW/NM-HA $15^{\top}$

Natrarchaeobaculum sulfurireducens AArc ${ }^{\top}$

Natrarchaeobius chitinivorans AArcht $4{ }^{\top}$

Natrarchaeobius halalkaliphilus AArcht-SI ${ }^{\top}$
CP031298.1, CP031299.1,

CP031300.1, СP031301.1

CP031302.1, CP031304.1

(plasmids)

AOIT00000000.1

JAHUQE0000000000.1

JHUT00000000.2

LWLN00000000.1

RQWN00000000.1

AOIS00000000.1

SMZK00000000.1

AOIR00000000.1

NC_013743.1

LKCV00000000.1

AOIQ00000000.1

NC_019964.1

CP019893.1

CP024047.1

REGA00000000.1

REFY00000000.1 
TABLE 1 | (Continued)

\begin{tabular}{|c|c|c|c|c|c|c|c|c|c|c|}
\hline Strain & Accession no. & Assembly & Level & Size (Mb) & GC $\%$ & Scaffolds & Contigs & CDS & N50 & L50 \\
\hline Natrialba aegyptia DSM $13077^{\top}$ & AOIP00000000.1 & GCA_000337535.1 & Contig & 4.62 & 62.0 & 66 & 66 & 4429 & 145,225 & 7 \\
\hline Natrialba asiatica DSM $12278^{\top}$ & AOIO00000000.1 & GCA_000337555.1 & Contig & 4.40 & 62.4 & 49 & 49 & 4188 & 174,934 & 7 \\
\hline Natrialba chahannaoensis JCM 10990 ${ }^{\top}$ & AOIN00000000.1 & GCA_000337135.1 & Contig & 4.31 & 60.4 & 106 & 106 & 4030 & 129,612 & 13 \\
\hline Natrialba hulunbeirensis JCM $10989^{\top}$ & AOIM00000000.1 & GCA_000337575.1 & Contig & 4.16 & 61.7 & 48 & 48 & 3834 & 159,578 & 8 \\
\hline Natrialba magadii ATCC 43099 & NC_013922.1 & GCA_000025625.1 & Complete & 4.44 & 61.0 & 4 & 4 & 4154 & $3,751,858$ & 1 \\
\hline Natrialba swarupiae ESP3B_9 ${ }^{\top}$ & VTAW00000000.1 & GCA_008245225.1 & Contig & 4.20 & 62.5 & 99 & 99 & 3969 & 129,190 & 11 \\
\hline Natrialba taiwanensis DSM $12281^{\top}$ & AOIL00000000.1 & GCA_000337595.1 & Contig & 4.64 & 61.5 & 70 & 70 & 4399 & 199,614 & 9 \\
\hline Natrinema altunense $\mathrm{AJ} 2^{\top}$ & JNCS00000000.1 & GCA_000731985.1 & Contig & 3.77 & 64.6 & 20 & 20 & 3688 & 425,349 & 4 \\
\hline Natrinema altunense 1A4-DGR & JXANO0000000.1 & GCA_000815265.1 & Contig & 3.72 & 64.8 & 215 & 215 & 5159 & 33,862 & 34 \\
\hline Natrinema altunense 4.1R & SHMR00000000.1 & GCA_004209855.1 & Scaffold & 3.67 & 64.9 & 12 & 81 & 3631 & $1,929,556$ & 1 \\
\hline Natrinema altunense JCM $12890^{\top}$ & AOIK00000000.1 & GCA_000337155.1 & Contig & 3.77 & 64.5 & 52 & 52 & 3698 & 184,807 & 7 \\
\hline Natrinema ejinorense JCM $13890^{\top}$ & NXNI00000000.1 & GCA_002494345.1 & Contig & 4.48 & 63.9 & 3 & 3 & 4337 & $3,988,345$ & 1 \\
\hline Natrinema gari JCM $14663^{\top}$ & AOIJ000000000.1 & GCA_000337175.1 & Contig & 4.02 & 63.7 & 88 & 88 & 3997 & 126,340 & 11 \\
\hline Natrinema pallidum BOL6-1 & СР040637.1 & GCA_005890195.1 & Complete & 3.78 & 64.3 & 3 & 3 & 3723 & $3,503,953$ & 1 \\
\hline Natrinema pallidum DSM $3751^{\top}$ & AOII00000000.1 & GCA_000337615.1 & Contig & 3.92 & 63.7 & 115 & 115 & 3852 & 88,603 & 17 \\
\hline Natrinema pellirubrum DSM $15624^{\top}$ & $\begin{array}{l}\text { NC_019962.1 (chromosome), } \\
\text { NC_019963.1, NC_019967.1 } \\
\text { (plasmids) }\end{array}$ & GCA_000230735.3 & Complete & 4.35 & 64.0 & 3 & 3 & 4249 & $3,790,479$ & 1 \\
\hline Natrinema salaciae DSM $25055^{\top}$ & FOFD00000000.1 & GCA_900110865.1 & Scaffold & 4.86 & 65.0 & 11 & 15 & 4634 & 865,606 & 3 \\
\hline "Natrinema thermophila" CBA1119 & PDBS00000000.1 & GCA_002572525.1 & Contig & 5.06 & 62.3 & 9 & 9 & 4965 & $4,087,412$ & 1 \\
\hline Natrinema sp. J7-1 & AJVG00000000.1 & GCA_000493245.1 & Contig & 3.67 & 64.4 & 42 & 42 & 3632 & 196,646 & 6 \\
\hline Natrinema sp. J7-2 & NC_018224.1 & GCA_000281695.1 & Complete & 3.79 & 64.1 & 2 & 2 & 3706 & $3,697,626$ & 1 \\
\hline Natrinema versiforme BOL5-4 & СР040330.1 & GCA_005576615.1 & Complete & 4.67 & 63.4 & 5 & 5 & 4514 & $3,747,116$ & 1 \\
\hline Natrinema versiforme JCM $10478^{\top}$ & AOID00000000.1 & GCA_000337195.1 & Contig & 4.19 & 64.0 & 72 & 72 & 4146 & 121,463 & 13 \\
\hline Natronobacterium gregoryi SP2 ${ }^{\top}$ & NC_019792.1 & GCA_000230715.3 & Complete & 3.79 & 62.2 & 1 & 1 & 3710 & $3,788,356$ & 1 \\
\hline Natronobacterium texcoconense DSM $24767^{\top}$ & FNLC00000000.1 & GCA_900104065.1 & Scaffold & 4.01 & 62.9 & 9 & 10 & 3976 & $1,245,734$ & 2 \\
\hline Natronococcus amylolyticus DSM 10524 & AOIB00000000.1 & GCA_000337675.1 & Contig & 4.42 & 64.4 & 44 & 44 & 4320 & 232,276 & 7 \\
\hline Natronococcus jeotgali DSM $18795^{\top}$ & AOIA00000000.1 & GCA_000337695.1 & Contig & 4.50 & 64.4 & 170 & 170 & 4458 & 76,066 & 20 \\
\hline Natronococcus occultus SP4 $4^{\top}$ & NC_019974.1 & GCA_000328685.1 & Complete & 4.31 & 64.6 & 3 & 3 & 4174 & $4,013,216$ & 1 \\
\hline Natronolimnobius baerhuensis CGMCC $1.3597^{\top}$ & MWPH00000000.1 & GCA_002177135.1 & Contig & 3.91 & 60.2 & 8 & 8 & 3745 & $1,261,254$ & 2 \\
\hline Natronolimnohabitans innermongolicus JCM $12255^{\top}$ & AOHZOOO00000.1 & GCA_000337215.1 & Contig & 4.59 & 64.3 & 121 & 121 & 4384 & 96,333 & 18 \\
\hline Natronorubrum aibiense $7-3^{\top}$ & СР045488.1 & GCA_009392895.1 & Complete & 4.35 & 61.3 & 4 & 4 & 4130 & $3,352,994$ & 1 \\
\hline Natronorubrum bangense JCM $10635^{\top}$ & AOHY00000000.1 & GCA_000337715.1 & Contig & 4.11 & 60.4 & 62 & 62 & 3982 & 138,654 & 10 \\
\hline Natronorubrum sediminis CGMCC $1.8981^{\top}$ & FNWL00000000.1 & GCA_900108095.1 & Scaffold & 3.78 & 61.1 & 6 & 9 & 3583 & $1,300,740$ & 2 \\
\hline Natronorubrum sulfidifaciens JCM $14089^{\top}$ & AOHX00000000.1 & GCA_000337735.1 & Contig & 3.46 & 61.8 & 63 & 63 & 3408 & 225,522 & 5 \\
\hline Natronorubrum texcoconense $\mathrm{B}^{\top}$ & FNFE00000000.1 & GCA_900100335.1 & Contig & 4.64 & 63.6 & 11 & 11 & 4423 & 457,630 & 3 \\
\hline "Natronorubrum thiooxidans" HArc & FTNR00000000.1 & GCA_900156475.1 & Scaffold & 4.21 & 60.9 & 62 & 63 & 4067 & 250,216 & 6 \\
\hline Natronorubrum tibetense $\mathrm{GA} 3^{\top}{ }^{\top}$ & ARPH00000000.1 & GCA_000383975.1 & Scaffold & 4.93 & 62.3 & 5 & 10 & 4649 & $4,057,512$ & 1 \\
\hline
\end{tabular}


reads (SIPERs) and $2 \times 301$-bp long-insert paired-end reads (LIPERs). Downstream analyses were carried out as previously described (Ramírez-Durán et al., 2020). In brief, sequencing reads were quality filtered and trimmed using BBTools v.38.44 (Bushnell, 2020) and then assembled with SPAdes v.3.13.0 (Bankevich et al., 2012) using combined SIPERs and LIPERs as input. Automatic annotation of the draft genome was achieved using PGAP (Haft et al., 2018) as indicated above, that includes prediction of protein-coding genes, as well as other functional genome units such as structural RNAs, tRNAs, small RNAs and pseudogenes using a combination of $a b$ initio gene prediction algorithms with homology based methods.

\section{Phylogenetic and Phylogenomic Treeing}

The 16S rRNA gene sequences from the type strains of species of the family Natrialbaceae were downloaded from GenBank/EMBL/DDBJ databases or extracted from the whole genome sequences and then, aligned and used to calculate similarity matrixes and to construct neighbor-joining (NJ) (Saitou and Nei, 1987), maximum-parsimony (MP) (Fitch, 1971), and maximum-likelihood (MP) (Felsenstein, 1981) phylogenetic trees in ARB v.6.0.5 software package (Westram et al., 2011). Jukes-Cantor model of DNA evolution (Jukes and Cantor, 1969) was selected to correct the distance matrix. General Time Reversible model (Tavaré, 1986) with gamma-distribution and proportion of invariant sites to estimate rate heterogeneity over sites $(\mathrm{GTR}+\Gamma+\mathrm{I})$ was used to infer ML phylogeny. Branch support was assessed by 1,000 bootstrap pseudo-replicates (Felsenstein, 1985).

Since 16S rRNA gene-based phylogenies have been demonstrated not to be reliable to determine in-depth evolutionary relationships within the class Halobacteria and their results must be regarded with caution and carefully checked (Papke, 2009; Corral et al., 2018; de la Haba et al., 2018; Infante-Domínguez et al., 2020), a more robust and accurate phylogenomic approach was attempted. Firstly, panand core-genome datasets were determined using an all-vs.-all Blastp comparison among the translated CDS features of the annotated genomes under study, as previously described (de la Haba et al., 2019). Then, translated single-copy core gene sequences were individually aligned with Muscle (Edgar, 2004) and concatenated into a super-protein alignment, which was further analyzed to generate the phylogenomic tree by means of the approximately maximum-likelihood algorithm implemented in FastTreeMP v.2.1.8 (Price et al., 2010). Jones-Taylor-Thornton model of amino acid evolution (Jones et al., 1992) with a single rate for each site (JTT + CAT) was applied for phylogenomic reconstruction. Tree branch support was inferred using the Shimodaira-Hasegawa test (Shimodaira and Hasegawa, 1999).

Both, 16S rRNA gene-based and phylogenomic trees, were managed, displayed and annotated using the online tool iTOL v.5.7 (Letunic and Bork, 2021).

\section{Comparative Genomic Analyses}

Overall Genome Relatedness Indexes (OGRI) were calculated for all-vs.-all genome pairs. Specifically, Orthologous Average Nucleotide Identity (OrthoANI) was determined using the
OrthoANIu Tool (Yoon et al., 2017) which depends on USEARCH v8.1.1861, the digital DNA-DNA hybridization $(\mathrm{dDDH})$ was inferred by means of the Genome-to-Genome Distance Calculator (GGDC) (formula 2) (Meier-Kolthoff et al., 2013), the Average Amino-acid Identity (AAI) was estimated using the aai.rb script from the Enveomics collection (Rodriguez$\mathrm{R}$ and Konstantinidis, 2016) and, finally, the Percentage Of Conserved Proteins (POCP) was calculated with a homemade Perl script as described elsewhere (Qin et al., 2014).

Synteny analysis among selected representative genomes within the family Natrialbales was carried out to detect conservation of homologous genes and gene order across closed relatives. Because synteny can be affected by sequence fragmentation (Liu et al., 2018), draft genome contigs were reordered prior to infer synteny blocks using a gold standard genome (i.e., complete genome sequence) of a closely related species as a reference, using the Mauve Contig Mover functionality (Rissman et al., 2009). Conserved blocks were identified after Blastn pairwise comparisons (e-value $\leq 10^{-3}$ ) between the rearranged genomes and synteny plots were visualized using Easyfig v.2.2.3 (Sullivan et al., 2011).

\section{RESULTS AND DISCUSSION}

\section{The 16S rRNA Gene Sequence Analysis Unveils the Taxonomic Problems Arising Within the Genera Haloterrigena and Natrinema}

To gain a general overview of the current taxonomic situation of the family Natrialbaceae we reconstructed a phylogeny based on the 16S rRNA gene sequences (the most widely used molecular marker in modern prokaryotic systematics) including all type strains of the species with validly published names within that family (Figure 1). As hinted at previous studies (Tindall, 2003; Wright, 2006; Gupta et al., 2016), our results confirm that neither the genus Natrinema nor the genus Haloterrigena constituted monophyletic groups, but the constituent species of both genera were intermingled into a single monophyletic cluster, with the exception of the species Haloterrigena daqingensis which clustered together to Natronorubrum sediminis and Natronococcus roseus, distantly related to the rest of the species of Natrinema/Haloterrigena. Other problematic (polyphyletic or paraphyletic) genera within this family were Halovivax, Natrialba, Natronococcus, and Natronorubrum (Figure 1).

The 16S rRNA gene sequence similarities among the type species within the genera Natrinema and Haloterrigena, independently considered, ranged between $99.5-95.3 \%$ and 99.0-94.4\%, respectively, while the sequence similarities between both genera varied from 99.0 to $94.6 \%$, by far above the threshold value for differentiating prokaryotic genera (<94.5\%) (Yarza et al., 2014). Therefore, intra- and inter-genera sequence similarities overlap almost entirely, which indicates a rather fuzzy delineation between those two genera. With regards to species delineation, the following monophyletic groups sharing equal or more than $98.65 \%$ 


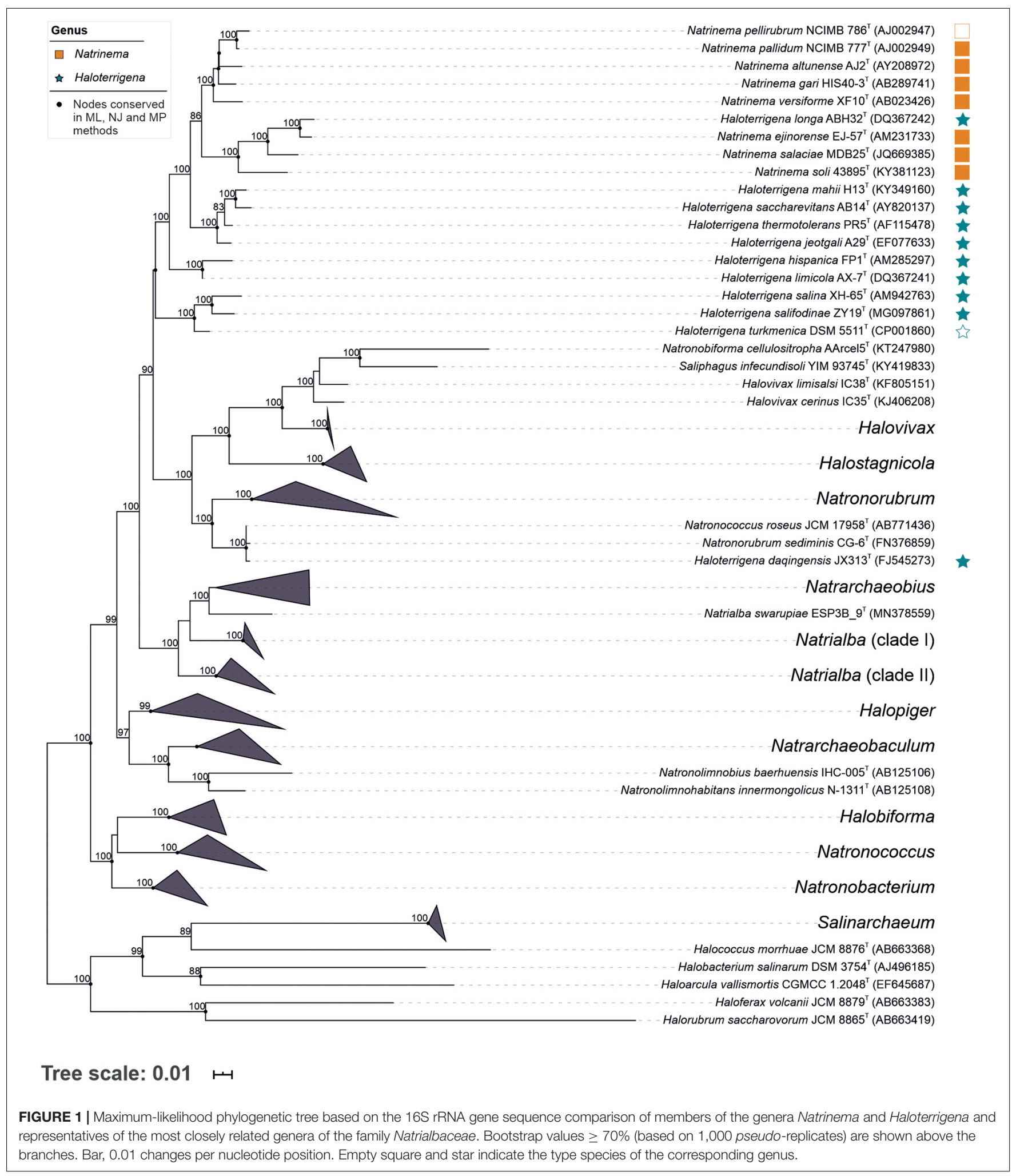

sequence similarity (generally accepted as the prokaryotic species cutoff value) (Kim et al., 2014) could be observed: Natrinema pellirubrum-Natrinema pallidum; Natrinema ejinorenseHaloterrigena longa; Haloterrigena mahii-Haloterrigena
saccharevitans-Haloterrigena thermotolerans; Haloterrigena hispanica-Haloterrigena limicola; Haloterrigena daqingensisNatronococcus roseus-Natronorubrum sediminis. Besides, other potential species synonymy could be detected in the family 
Natrialbaceae: Halobiforma haloterrestris_Halobiforma lacisalsi; Halopiger aswanensis-Halopiger thermotolerans-Halopiger xanaduensis; Halostagnicola alkaliphila-Halostagnicola bangensis; Halovivax asiaticus - Halovivax ruber; and Natrialba aegyptia-Natrialba taiwanensis-Natrialba asiatica. Despite that different species could sometimes share values above the indicated threshold, the groups mentioned here should be carefully checked to detect the existence of synonymy.

\section{Taxophylogenomics and Overall Genome Related Indexes Values Prove the Proposal to Keep the Genera Natrinema and Haloterrigena as Separated Taxa}

To confirm the results noted after 16S rRNA gene sequence analysis, a more robust and determinative phylogenomic analysis was carried out. For that purpose, all genome sequences from type strains of the species of the family Natrialbaceae as well as other non-type strains of the genera Natrinema and Haloterrigena available in NCBI GenBank database at the time of the study were recovered. Since the genome data for the type strain of Haloterrigena longa could not be retrieved and because this species requested special attention given its close relationship to Natrinema ejinorense (as indicated above), we sequenced and analyzed it. A total of $\sim 0.32$ and $\sim 2.12 \mathrm{~Gb}$ from pairedend and mate pair libraries, respectively, were obtained after trimming and filtering. Average insert size was computationally estimated to be $\sim 550$ bp for paired-end and $\sim 2,000$ bp for mate pair datasets. Assembly yielded a $4.13 \mathrm{Mb}, 6$ scaffolds genome with a N50 of 3,590,587 bp and a coverage of 78X. Table 1 shows all the genome sequences used in this study, as well as their main features.

Phylogenomic trees inferred from the concatenation of the 525 amino acid sequences of the orthologous single-copy genes present in the type strain genomes (Figure 2) and in all the genomes under study (Supplementary Figure 1) were obtained. A previous study focused on the evolution of the class Halobacteria has also reported phylogenomic core trees that concurs with our results, although those phylogenetic reconstructions were based on only 45 orthologous core genes and did not include all the representative genomes within the Natrialbales (Gaba et al., 2020). As might be expected, the topology of our phylogenomic tree was not totally in agreement to the $16 \mathrm{~S}$ rRNA gene phylogeny, but the clusters obtained were better supported in the phylogenomic tree, with 100\% bootstrap in almost all bifurcations. Most significantly, the strains from the cluster Natrinema/Haloterrigena (which could not be distinguished either from each other, as in the 16S rRNA tree) did not form a monophyletic group, even when excluding the species Haloterrigena daqingensis. In particular, Haloterrigena turkmenica (the type species of the genus), Haloterrigena salifodinae, and Haloterrigena salina clustered together and separated from the other Natrinema/Haloterrigena members. Therefore, our results indicate that merging both genera is not convenient, while transferring some current Haloterrigena species (i.e., Htg. hispanica, Htg. jeotgali, Htg. limicola, Htg. longa, Htg. mahii, Htg. saccharevitans, Htg. thermotolerans) to the genus Natrimena seems more appropriate. That way the genus Haloterrigena would remain composed of the species Htg. turkmenica, Htg. salina, and Htg. salifodinae. Furthermore, the species Haloterrigena daqingensis formed a monophyletic group with all the Natronorubrum species, thus suggesting its reclassification as a member of the latter genus. It is worth noting that the species Halopiger salifodinae did not affiliate with the other Halopiger species but was closely related to the Natrinema/Haloterrigena group. This taxon might belong, indeed, to the latter group or, alternatively, it might constitute a new separate genus within the Natrialbaceae. In order to unravel this issue, an in-depth analysis of OGRI values may be determinative.

The reference non-type strains whose genome sequences were included in this study showed that all of them clustered together to their respective type strain, except for the strain Haloterrigena turkmenica WANU15, which might be part of the genus Natronolimnohabitans; however, it must be noted that the genome sequence of Haloterrigena turkmenica WANU15 has been confirmed to be contaminated (Lee et al., 2017) and, thus, this result must be observed with caution. Concerning the unnamed strains analyzed (i.e., Natrinema sp. J-1, Natrinema sp. $\mathrm{J}-2$, and Haloterrigena sp. H1), the two first probably belong to the species Natrinema gari, whereas the latter might be regarded as a new species into the Natrinema/Haloterrigena archaeal set. Phylogenomic tree also uncover some other taxonomic problems arising within the Natrialbaceae, such as the polyphyly of the genera Natrialba and Halopiger, but they are out of the scope of this study.

Aimed to shed light on the classification of the Natrialbaceae, several OGRI types were calculated, in particular those mostly accepted to delineate taxa at the prokaryotic genus and species level. Methods to demarcate genera have been proposed that are based on either AAI (Konstantinidis and Tiedje, 2007) or the POCP (Qin et al., 2014). The former approach sets a cutoff value for genus demarcation of $65 \%$ AAI (Konstantinidis et al., 2017); however, this threshold cannot be universally employed for all bacterial and archaeal lineages. In fact, if we would use the 65\% AAI cutoff all the genera within the Natrialbaceae, apart from the genus Halovivax, should be merged in a single one since they shared AAI values equal or above 67\% (Figure 3 and Supplementary Figure 2). Therefore, AAI values might be useful for genera demarcation in this family, but a different boundary needs to be established for it. Previous studies have pointed out the convenience to set lineage specific OGRI limits to define prokaryotic genera (Barco et al., 2020). Genus demarcation boundaries were determined for the family Natrialbaceae after detailed inspection of AAI values for all pairwise genome comparisons (Figure 3 and Supplementary Figure 2), in agreement with the phylogenomic trees (Figure 2 and Supplementary Figure 1), to avoid the existence of polyphyletic genera. Thus, we propose a cutoff value of $\leq 76 \%$ AAI to differentiate genera within the family Natrialbaceae, a robust and consistent threshold according to the observed evolutionary relationships among members of this family. By using this threshold, the species Haloterrigena turkmenica, 


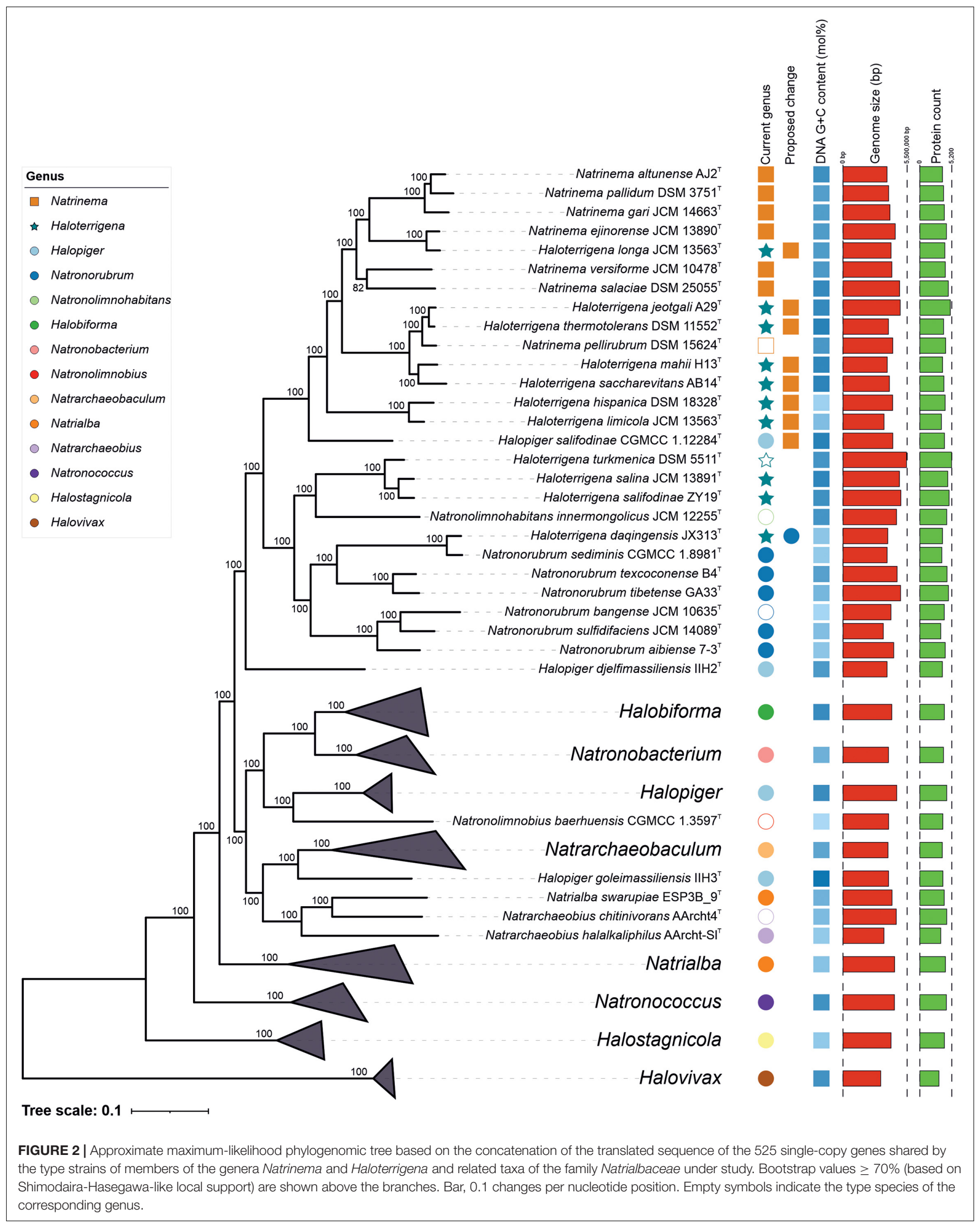




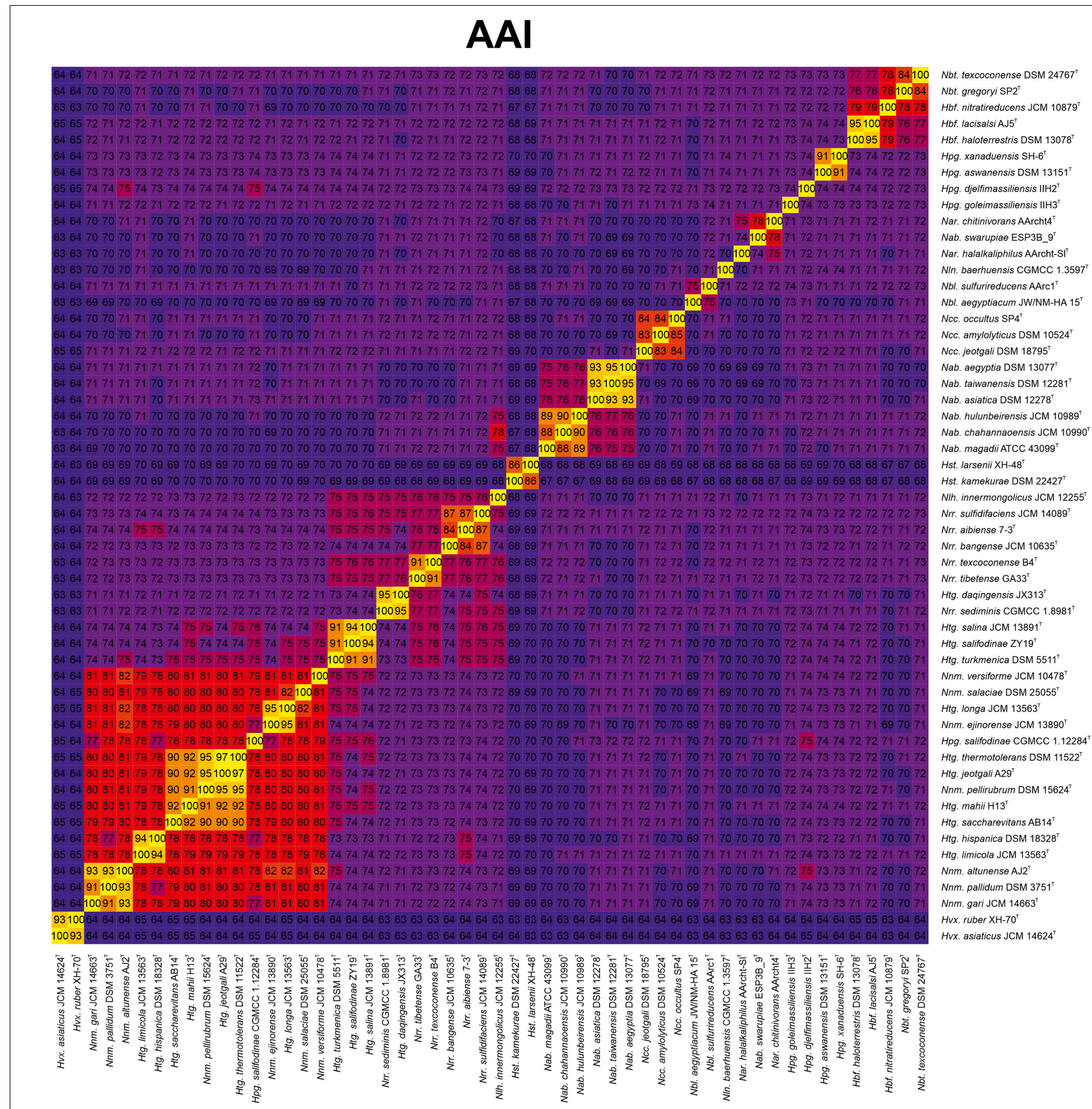

FIGURE 3 | Heatmap of AAl relatedness among the type strains of members of the genera Natrinema and Haloterrigena and representatives of the other genera of the family Natrialbaceae.

Haloterrigena salifodinae, and Haloterrigena salina will be retained as the only members of Haloterrigena. Moreover, the species Haloterrigena daqingensis should be transferred to the genus Natronorubrum. Finally, the remaining species of Haloterrigena, the species Halopiger salifodinae and all the Natrinema species should be joined together into a single genus. Since the genus Natrinema has priority over the other two, all the aforementioned species should be reclassified as members of Natrinema. Our proposed genus limit should also have consequences in the taxonomic status of other genera of the family Natrialbaceae, such as the convenience to merge the genera Halobiforma and Natronobacterium, the transfer of Natrialba swarupia into the genus Natrarchaeobius and the need to revisit the affiliation of Halopiger goleimassiliensis and Halopiger djelfimassiliensis outside the genus Halopiger. Nevertheless, additional studies including all the type strains of the species of those genera is required, which is beyond the subject of the present article. 
On the other hand, the POCP method sets a genus boundary at a value of 50\% (Qin et al., 2014). Nevertheless, that limit cannot be applied to the family Natrialbaceae since all the constituent genera shared values above it. It has been discussed that this cutoff value was arbitrarily established (Barco et al., 2020), so, according to our results (Supplementary Figure 3) we can propose a threshold at a POCP value of $<66 \%$ for genus demarcation in this family. Nevertheless, this genomic index seems not to be as accurate as AAI and in borderline cases interpretation of results may be unclear. For example, the group formed by Haloterrigena turkmenica, Haloterrigena salifodinae, and Haloterrigena salina (which seemed to constitute an independent genus as explained above) could not be clearly separated from the Haloterrigena daqingensis/Natronorubrum spp. cluster, from the genus Natronolimnohabitans, or from the rest of the strains of the Natrinema/Haloterrigena clade using our proposed POCP-based genus cutoff. Another outlier was the low POCP values of the strain Natrinema altunense 1A4-DGR with respect to most of the strains within the Natrinema/Haloterrigena cluster, indicating some confidence issues for this index. Besides, other genera within the family Natrialbaceae that could not be distinguished using POCP index but whose unification is not supported by phylogenomic tree were NatrarchaeobaculumNatrarchaeobius-Natronolimnobius; Halobiforma-Halopiger. Hence, we discourage taxonomist from using POCP method to define genera within the family Natrialbaceae.

A longer list of OGRI has been proposed to be useful for prokaryotic species delineation (Palmer et al., 2020), such as AAI (Konstantinidis and Tiedje, 2005) -which can also be employed for genus demarcation-, ANIb (Goris et al., 2007), ANIm, TETRA (Richter and Rossello-Mora, 2009), MUMi (Deloger et al., 2009), dDDH (Meier-Kolthoff et al., 2013), gANI, alignment fraction (Varghese et al., 2015), OrthoANI (Lee et al., 2016), and FastANI (Jain et al., 2018). Among them, two of the most widely used for taxonomic purposes at species level are dDDH and OrthoANI, with widely accepted cutoff values of 70\% (Auch et al., 2010) and 95-96\% (Goris et al., 2007; Richter and Rossello-Mora, 2009; Chun and Rainey, 2014), respectively. We calculated these two OGRI for the family Natrialbaceae (Figure 4 and Supplementary Figure 4) with the aim to identify the existence of synonymy between recognized species names and to properly affiliate unnamed strains to a species. A first glimpse of OrthoANI/dDDH results showed several borderline genome pairs (94\% OrthoANI and $\sim 55 \% \mathrm{dDDH}$ ) in our dataset, in particular Haloterrigena hispanica DSM $18328^{\mathrm{T}} /$ Haloterrigena limicola JCM $13563^{\mathrm{T}}$, Haloterrigena daqingensis $\mathrm{JX} 313^{\mathrm{T}} / \mathrm{CGMCC}$ $1.8909^{\mathrm{T}} /$ Natronorubrum sediminis CGMCC $1.8961^{\mathrm{T}}$, and Haloterrigena salifodinae $\mathrm{ZY} 19^{\mathrm{T}} /$ Haloterrigena salina JCM $13891^{\mathrm{T}}$, but they cannot be regarded as synonyms because they are still below the species threshold values and might indicate a recent speciation event. Following this criterion, the non-type strains Haloterrigena hispanica CDM_1 and Haloterrigena hispanica CDM_6 seemed to be misclassified and they should be described as a separated species from Haloterrigena hispanica, although a further descriptive characterization is required for this purpose. Unfortunately, none of both strains are available in public microbial culture collections. Similarly, the strain Haloterrigena sp. H1, sharing $\leq 89 \%$ OrthoANI and $\leq 39 \%$ $\mathrm{dDDH}$ values with respect to any of the analyzed strains in the family Natrialbaceae, constitutes a novel species within the cluster Natrinema/Haloterrigena, but access to the biological resource is needed before to make any formal proposal. Our study also indicated that the species "Natrinema thermophila" (Kim et al., 2018) and "Natronorubrum thiooxidans" (Sorokin et al., 2005) (names effectively but not validly published) should be unequivocally considered as novel taxa within their respective genera, although those names need to be validated beforehand. More uncertain was the taxonomic differentiation of several genome pairs within the fuzzy zone (95\% OrthoANI and $60-63 \% \mathrm{dDDH})$, specifically Natrinema pellirubrum DSM $15624^{\mathrm{T}} /$ Haloterrigena jeotgali $\mathrm{A} 29^{\mathrm{T}}$, Natrinema pellirubrum DSM $15624^{\mathrm{T}} /$ Haloterrigena thermotolerans DSM $11522^{\mathrm{T}}$, and Natrinema ejinorense JCM $13890^{\mathrm{T}} /$ Haloterrigena longa JCM $13563^{\mathrm{T}}$. Additionally, it must be noted that when using formula 1 and 3 (instead of formula 2) for dDDH calculation the results for the aforementioned genome pairs were $64-65 \%, 67-68 \%$, and $70 \%$, respectively, making more challenging their proper taxonomic classification. In those cases, the sole use of OGRI values was not discriminative enough as to make a decision on their taxonomy and additional genomic and phenotypic data must be provided. On the other hand, OrthoANI and $\mathrm{dDDH}$ values doubtlessly indicate that each of the following groups of strains belongs to the same species: Natrinema gari JCM $14663^{\mathrm{T}} /$ Natrinema sp. J7-1/Natrinema sp. J7-2, Natrinema pallidum DSM $3751^{\mathrm{T}} /$ Natrinema pallidum BOL6-1, Natrinema altunense JCM $12890^{\mathrm{T}} /$ Natrinema altunense $\mathrm{AJ} 2^{\mathrm{T}} /$ Natrinema altunense 4.1R/Natrinema altunense 1A4-DGR, Haloterrigena hispanica CDM_1/Haloterrigena hispanica CDM_6, Haloterrigena jeotgali $\mathrm{A} 29^{\mathrm{T}} /$ Haloterrigena thermotolerans DSM $11522^{\mathrm{T}}$, Haloterrigena daqingensis $\mathrm{JX} 313^{\mathrm{T}} /$ Haloterrigena daqingensis CGMCC $1.8909^{\mathrm{T}}$, and Natronolimnohabitans innermongolicus JCM $12255^{\mathrm{T}} /$ Haloterrigena turkmenica WANU15. Therefore, the species Haloterrigena jeotgali should be considered as a later heterotypic synonym of Haloterrigena thermotolerans and the strains Natrinema sp. J7-1, Natrinema sp. J7-2, and Haloterrigena turkmenica WANU15 should be renamed as Natrinema gari J7-1, Natrinema gari J7-2, and Natronolimnohabitans innermongolicus WANU15, respectively. Other putative ambiguous synonyms were detected, such as those for the species Natrialba aegyptia/Natrialba taiwanensis and Halobiforma haloterrestris/Halobiforma lacisalsi, but the convenience to be merged or not should be accomplished in future studies.

\section{Synteny Analysis Applied to Elucidation of Uncertain Synonyms Into the Natrinema/Haloterrigena}

The evolutionary processes that lead to diversity, chromosomal dynamics, and rearrangement rates between species can be assessed by means of the analysis of the synteny among two or more genomes, that is, the spatial distribution of locally collinear 


\section{OrthoANlu}

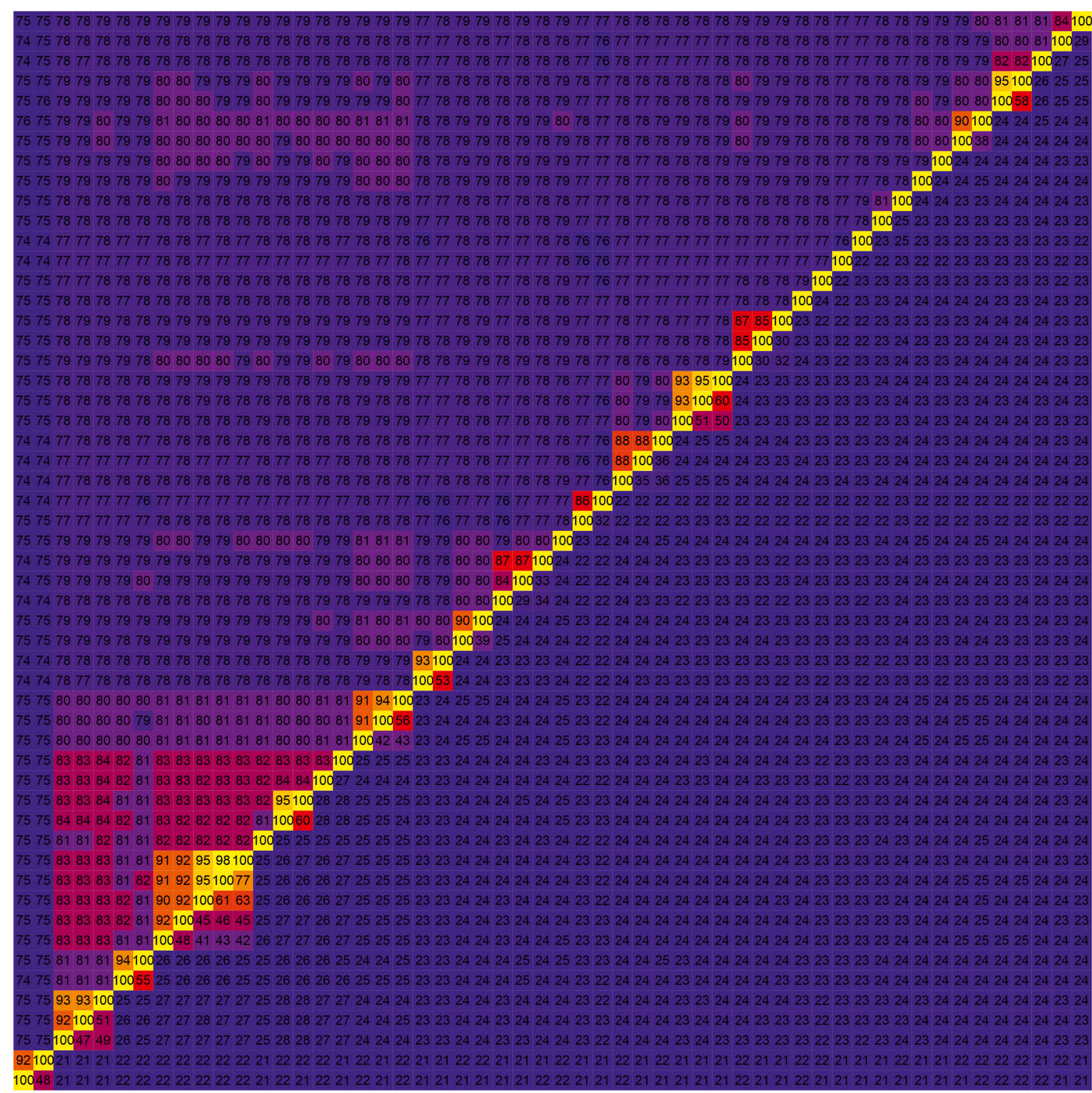

Nbt. texcoconense DSM $24767^{7}$ Nbt. gregoryi $\mathrm{SP2} 2^{\top}$

Hbf. nitratireducens JCM $10879^{\top}$ Hbf. lacisalsi AJ5 ${ }^{\top}$

Hbf. haloterrestris DSM $13078^{\top}$ Hpg. xanaduensis SH-6 Hpg. aswanensis DSM $13151^{\top}$ Hpg. djelfimassiliensis $\|^{1}{ }^{\top}$ Hpg. goleimassiliensis $\|_{\mathrm{H}^{3}}$ Nar. chitinivorans AArcht4 Nab. swarupiae ESP3B_9 $9^{7}$ Nar. halalkaliphilus AArcht-SI NIn. baerhuensis CGMCC 1.3597 Nbl. sulfurireducens AArc $^{\top}$ Nbl. aegyptiacum JW/NM-HA $15^{\top}$ Ncc. occultus $\mathrm{SP}^{\top}$

Noc. amylolyticus DSM 10524 Ncc. jeotgali DSM $18795^{\top}$ Nab. aegyptia DSM $13077^{\top}$ Nab. taiwanensis DSM 12281 Nab. asiatica DSM $12278^{\top}$ Nab. hulunbeirensis JCM $10989^{\top}$ Nab. chahannaoensis JCM $1090^{\circ}$ Nab. magadii ATCC $43099^{\prime}$ Hst. larsenii $\mathrm{XH}^{-48^{\top}}$ Hst. kamekurae DSM $22427^{\top}$ NIh. innermongolicus JCM $12255^{\circ}$ Nrr. sulfidifaciens JCM $14089^{\top}$ Nrr. aibiense 7-3 Nrr. bangense JCM 10635

Nrr. texcoconense B4 ${ }^{\top}$ Nrr. tibetense GA33 ${ }^{\mathrm{T}}$ Htg. daqingensis JX313 Nrr. sediminis CGMCC 1.898 Htg. salina JCM $13891^{\top}$

Htg. salifodinae $\mathrm{ZY} 19^{\top}$ Htg. turkmenica DSM $5511^{\top}$ Nnm. versiforme JCM $10478^{7}$ Nnm. salaciae DSM 25055 Htg. longa JCM 13563' Nnm. ejinorense JCM $13890^{\top}$ Hpg. salifodinae CGMCC $1.12284^{\top}$ Htg. thermotolerans DSM 11522 Htg. jeotgali A29

Nnm. pellirubrum DSM 15624 Htg. mahii $\mathrm{H} 13$

Htg. saccharevitans $\mathrm{AB} 14^{\top}$ Htg. hispanica DSM 18328 Htg. limicola JCM $13563^{\top}$ $\mathrm{Nnm}$. altunense $\mathrm{AJ}{ }^{\top}$ Nnm. pallidum DSM $3751^{\top}$ Nnm. gari JCM $14663^{\top}$ Hvx. ruber $\mathrm{XH}-70^{\top}$ Hvx. asiaticus JCM 14624

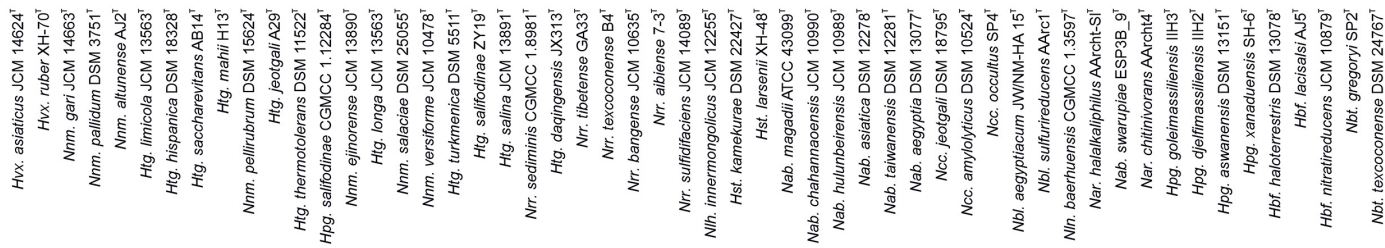

\section{dDDH}

FIGURE 4 | Heatmap of OrthoANlu (upper triangle) and dDDH (lower triangle) relatedness among the type strains of members of the genera Natrinema and Haloterrigena and representatives of the other genera of the family Natrialbaceae.

blocks (Bhutkar et al., 2006). Thus, an approach to gain insight into the evolutionary distance between two species is to inspect the synteny of the genome sequences under study (Borriss et al., 2011; Ramírez-Durán et al., 2021). As indicated in the previous section, OGRI values equal to the species cutoffs were not able to reliably solve the taxonomic status of several species and so, the synteny analysis might shed light to elucidate the affiliation of those uncertain taxa.
Specifically, we have evaluated, on the one hand, the synteny between Natrinema ejinorense JCM $13890^{\mathrm{T}}$ and Haloterrigena longa JCM $13563^{\mathrm{T}}$ and, on the other hand, the synteny among Natrinema pellirubrum DSM $15624^{\mathrm{T}}$, Haloterrigena jeotgali $\mathrm{A} 29^{\mathrm{T}}$, and Haloterrigena thermotolerans DSM $11522^{\mathrm{T}}$ (Figure 5). As can be observed, although some genomic rearrangements could be evidenced, all comparisons showed high levels of conservation of locally collinear blocks. It 


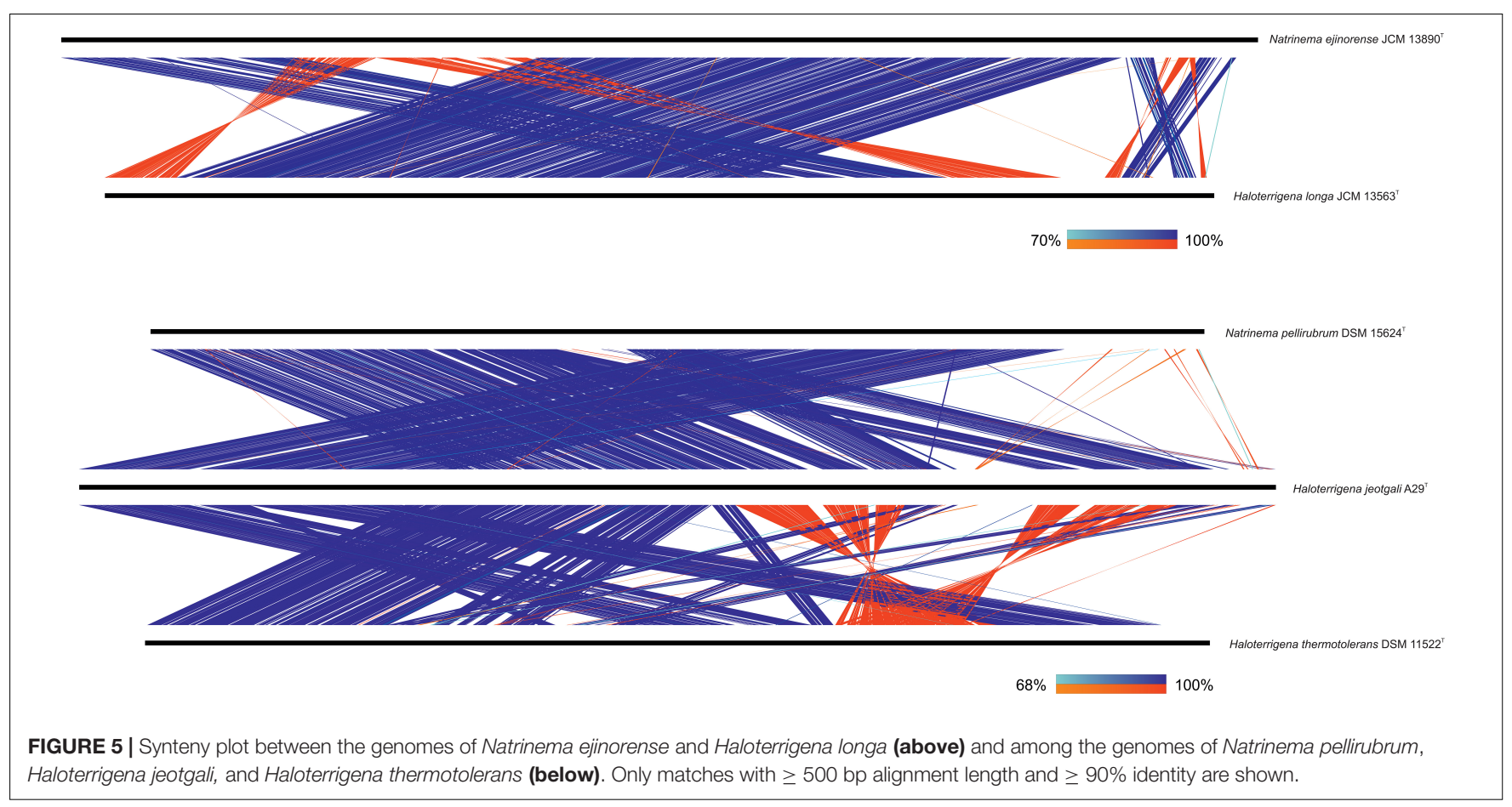

must be noted that the synteny between Haloterrigena jeotgali $\mathrm{A} 29^{\mathrm{T}}$ and Haloterrigena thermotolerans DSM $11522^{\mathrm{T}}$ seemed to be more disorganized than that for other genome pairs; however, this fact is due to the elevated fragmentation of the genome sequence from Haloterrigena thermotolerans DSM $11522^{\mathrm{T}}$ (68 scaffolds and a N50 of 162,183 bp), which reduces the robustness of the synteny analysis. In any case, the synteny results are not so relevant for such genome pair since OGRI values undoubtedly demonstrated the synonym between those species, as stated earlier. The other genome sequences analyzed here for synteny comparisons possessed high-quality, with a minimum N50 of $3.59 \mathrm{Mb}$ and, therefore, they met the requirements to be confidently used for this purpose (Liu et al., 2018).

Our results concerning the study of regions of local collinearity support the union of Natrinema ejinorense and Haloterrigena longa and of Natrinema pellirubrum and Haloterrigena jeotgali/Haloterrigena thermotolerans as a single species, respectively. Nevertheless, phenotypic features should also be considered before those proposals can be formulated.

\section{Phenotypic Characteristics Endorse the Taxonomic Rearrangements for the Genera Natrinema and Haloterrigena}

For an accurate classification of a taxon, three major premises should be fulfilled: (i) monophyly, (ii) genomic coherence, and (iii) phenotypic coherence (Rosselló-Móra and Amann, 2015). In the previous sections we have examined the two first criteria (phylogenetic/phylogenomic trees and OGRI/synteny), but any formal taxonomic proposal should also be supported by phenotypic characters.
The species Haloterrigena turkmenica, Haloterrigena salifodinae, and Haloterrigena salina, which we propose to be retained as members of the genus Haloterrigena, shared a bunch of characteristics (Table 2), such as the coccoid morphology, the red pigmentation, the resistance to lysis in distilled water, the high salt concentration for optimal growth $[>15 \%(\mathrm{w} / \mathrm{v}) \mathrm{NaCl}]$, the inability to produce gas from nitrate, to form indole and $\mathrm{H}_{2} \mathrm{~S}$, and to hydrolyze starch, gelatin and Tween 80 , the ability to use D-glucose, D-mannose and lactose as a sole carbon and energy sources, the presence of phosphatidylglycerol (PG), phosphatidylglycerol phosphate methyl ester (PGP-Me) and mannose-2,6-disulfate $(1 \rightarrow 2)$ glucose glycerol diether ( $S_{2}$-DGD-1) as membrane polar lipids, and the lack of phosphatidylglycerol sulfate (PGS). On the other hand, the species Haloterrigena daqingensis, which formed a monophyletic cluster with the species of the genus Natronorubrum, showed some phenotypic similarities with the species of the latter genus, remarkably, the haloalkaliphilic behavior, the inability to hydrolyze casein and to assimilate D-ribose, D-mannitol and sorbitol, the presence of PG and PGP-Me, and the absence of PGS (Table 2). Finally, the remaining species of Haloterrigena together to the species of the genus Natrinema and Halopiger salifodinae lysed in distilled water, grew optimally in media with $15-29 \%$ (w/v) $\mathrm{NaCl}$, utilized acetate but not D-mannitol as the only carbon and energy sources, and possessed PG and PGP-Me as major polar lipids (Table 2). Some differences in the minor polar lipid composition of this Natrinema/Haloterrigena/Halopiger salifodinae group can be observed, in particular, the presence of $\mathrm{S}_{2}$-DGD-1 glycolipid in some species and its absence in others, and the lack of PGS in several taxa but not in all of them. Although previous studies have shown that there are 
TABLE 2 | Main comparative phenotypic features among members of the genera Natrinema (including the species Halopiger salifodinae), Haloterrigena, and Natronorubrum.

\begin{tabular}{|c|c|c|c|c|c|c|c|c|c|}
\hline Characteristics & $\begin{array}{c}\text { Nnm. } \\
\text { altunense }^{\text {a }}\end{array}$ & $\begin{array}{c}\text { Nnm. } \\
\text { ejinorense }^{\mathrm{b}}\end{array}$ & Nnm. garic & $\begin{array}{l}\text { Nnm. } \\
\text { pallidum }^{\text {d }}\end{array}$ & $\begin{array}{c}\text { Nnm. } \\
\text { pellirubrum }^{\mathrm{d}}\end{array}$ & $\begin{array}{c}\text { Nnm. } \\
\text { salaciae }^{\text {e }}\end{array}$ & Nnm. solif & $\begin{array}{c}\text { Nnm. } \\
\text { versiforme }\end{array}$ & $\begin{array}{c}\text { Htg. } \\
\text { hispanica }^{h}\end{array}$ \\
\hline Morphology & Rods & Pleomorphic & Rods & Rods & Rods & Pleomorphic & Oval & Pleomorphic & Coccoid \\
\hline Cell size & $\begin{array}{c}0.8-1.2 \times \\
3.0-7.0\end{array}$ & $\begin{array}{c}0.8-2.0 \times \\
1.5-4.0\end{array}$ & $\begin{array}{c}0.5-0.8 \times \\
2.0-3.0\end{array}$ & $\begin{array}{c}0.7-1.0 \times \\
1.5-6.0\end{array}$ & $\begin{array}{c}0.6-1.0 \times \\
1.0-4.0\end{array}$ & $\begin{array}{c}0.8-1.5 \times \\
1.0-3.0\end{array}$ & $1.2-1.6$ & ND & $1.5-2.0$ \\
\hline Motility & + & - & + & + & + & - & - & - & - \\
\hline Colony pigmentation & Orange or red & Light red & Pale orange & $\begin{array}{l}\text { Pale orange, } \\
\text { beige or almost } \\
\text { colorless }\end{array}$ & $\begin{array}{l}\text { Light red or } \\
\text { orange }\end{array}$ & Red & Cream & Light red & Light red \\
\hline Cells lyse in distilled water & ND & ND & ND & ND & ND & ND & ND & ND & + \\
\hline $\mathrm{NaCl}$ range, \% (w/v) (optimum) & $>10(17.5-25)$ & $>10.5(20)$ & $>10(15-20)$ & $>10(20-25)$ & $>12(20-25)$ & $10-30(15-20)$ & $17.5-26(23)$ & $>9$ (20-25) & $13-23(20)$ \\
\hline $\mathrm{MgCl}_{2}$ requirement & + & - & - & ND & ND & - & - & + & - \\
\hline Temperature range (optimum) & $20-60(37-40)$ & $25-50(37)$ & $20-60(37-40)$ & $25-60(37-40)$ & $20-45(30-37)$ & $30-52.5(45)$ & $25-45(40)$ & $20-53(37-46)$ & $37-60(50)$ \\
\hline pH range (optimum) & $\begin{array}{c}6.0-8.0 \\
(7.0-7.7)\end{array}$ & $6.0-8.5(7.0)$ & $\begin{array}{l}5.5-8.5 \\
(6.0-6.5)\end{array}$ & $\begin{array}{c}6.0-8.4 \\
(7.2-7.6)\end{array}$ & $\begin{array}{c}6.0-8.6 \\
(7.2-7.8)\end{array}$ & $\begin{array}{c}6.5-9.0 \\
(7.0-8.0)\end{array}$ & $6.0-8.0(7.0)$ & $\begin{array}{l}6.0-8.0 \\
(6.5-7.0)\end{array}$ & $6.5-8.5(7.0)$ \\
\hline \multicolumn{10}{|c|}{ Anaerobic growth in presence of: } \\
\hline Nitrate & + & - & - & + & - & + & - & + & ND \\
\hline L-arginine & ND & - & ND & ND & ND & - & - & ND & ND \\
\hline Oxidase & + & + & + & + & - & + & - & + & + \\
\hline Catalase & + & + & + & ND & ND & + & + & ND & + \\
\hline Nitrate reduction to nitrite & + & + & - & + & + & + & - & + & + \\
\hline Gas from nitrate & + & + & - & - & - & ND & ND & + & ND \\
\hline Indole production & - & - & - & - & - & ND & - & + & + \\
\hline $\mathrm{H}_{2} \mathrm{~S}$ production & + & - & ND & - & - & ND & - & + & + \\
\hline \multicolumn{10}{|l|}{ Hydrolysis of: } \\
\hline Starch & - & + & - & - & - & + & - & \pm & - \\
\hline Casein & - & - & - & ND & ND & + & - & - & - \\
\hline Gelatin & + & + & + & + & + & + & - & - & - \\
\hline Tween 80 & + & + & - & + & - & ND & + & + & - \\
\hline
\end{tabular}


TABLE 2 | (Continued)

\begin{tabular}{|c|c|c|c|c|c|c|c|c|c|}
\hline Characteristics & $\begin{array}{c}\text { Nnm. } \\
\text { altunense }^{\mathrm{a}}\end{array}$ & $\begin{array}{c}\text { Nnm. } \\
\text { ejinorense }^{\mathrm{b}}\end{array}$ & Nnm. garic & $\begin{array}{c}\text { Nnm. } \\
\text { pallidum }^{\text {d }}\end{array}$ & $\begin{array}{c}\text { Nnm. } \\
\text { pellirubrum }^{\text {d }}\end{array}$ & $\begin{array}{c}\text { Nnm. } \\
\text { salaciae }^{\mathrm{e}}\end{array}$ & Nnm. solif & $\begin{array}{c}\text { Nnm. } \\
\text { versiforme }\end{array}$ & $\begin{array}{c}\text { Htg. } \\
\text { hispanica }^{\mathrm{h}}\end{array}$ \\
\hline \multicolumn{10}{|c|}{ Utilization as sole carbon and energy source of: } \\
\hline Acetate & + & + & ND & ND & ND & + & ND & ND & + \\
\hline D-Glucose & + & + & + & + & + & - & + & + & - \\
\hline D-Fructose & - & + & ND & + & + & - & ND & + & - \\
\hline D-Galactose & - & - & ND & ND & ND & - & + & + & - \\
\hline D-Mannose & + & - & - & ND & ND & - & - & + & - \\
\hline D-Ribose & - & - & - & - & + & - & - & + & - \\
\hline D-Xylose & - & - & - & ND & ND & - & - & + & - \\
\hline Sucrose & - & + & - & ND & ND & - & - & + & - \\
\hline Maltose & + & + & - & ND & ND & - & + & + & - \\
\hline Lactose & - & - & - & + & + & - & - & - & ND \\
\hline Glycerol & + & + & + & ND & ND & - & ND & + & + \\
\hline Sorbitol & ND & - & - & ND & ND & - & - & ND & ND \\
\hline D-Mannitol & ND & - & - & ND & ND & - & - & ND & ND \\
\hline \multicolumn{10}{|c|}{ Acid production from: } \\
\hline D-Mannose & + & - & ND & ND & ND & + & - & ND & ND \\
\hline D-Glucose & + & - & ND & ND & ND & + & - & ND & ND \\
\hline \multicolumn{10}{|l|}{ Lipids: } \\
\hline Major polar lipids & PG, PGP-Me & PG, PGP-Me & PG, PGP-Me & PG, PGP-Me & PG, PGP-Me & PG, PGP-Me & PG, PGP-Me & PG, PGP-Me & PG, PGP-Me \\
\hline Major glycolipids & $\begin{array}{l}\text { Unidentified } \\
\text { glycolipid }\end{array}$ & $\mathrm{S}_{2}-\mathrm{DGD}-1$ & $\begin{array}{l}\text { Unidentified } \\
\text { glycolypids }\end{array}$ & $\begin{array}{l}\text { Unidentified } \\
\text { glycolypids }\end{array}$ & $\begin{array}{l}\text { Unidentified } \\
\text { glycolypids }\end{array}$ & $\mathrm{S}_{2}$-DGD-1 & $\mathrm{S}_{2}-\mathrm{DGD}-1$ & $\begin{array}{l}\text { Unidentified } \\
\text { glycolypids }\end{array}$ & S-DGD-1 \\
\hline Presence of PGS & + & - & + & + & + & + & - & + & - \\
\hline
\end{tabular}


TABLE 2 | (Continued)

\begin{tabular}{|c|c|c|c|c|c|c|c|c|c|c|}
\hline Characteristics & $\begin{array}{c}\text { Htg. } \\
\text { jeotgali }\end{array}$ & $\begin{array}{c}\text { Htg. } \\
\text { limicola }\end{array}$ & $\begin{array}{l}\text { Htg. } \\
\text { longa }\end{array}$ & $\begin{array}{c}\text { Htg. } \\
\text { mahiik }\end{array}$ & $\begin{array}{c}\text { Htg. } \\
\text { saccharevitans }\end{array}$ & $\begin{array}{l}\text { Htg. } \\
\text { thermotolerans }^{\mathrm{m}}\end{array}$ & $\begin{array}{c}\text { Hpg. } \\
\text { salifodinae }^{n}\end{array}$ & $\begin{array}{c}\text { Htg. } \\
\text { salifodinae }^{\circ}\end{array}$ & $\begin{array}{c}\text { Htg. } \\
\text { salina }^{p}\end{array}$ & $\begin{array}{c}\text { Htg. } \\
\text { turkmenica }\end{array}$ \\
\hline Morphology & Rods & Rods & Rods & Rods & Rods & Rods & Pleomorphic & $\begin{array}{c}\text { Coccoid or } \\
\text { oval }\end{array}$ & Coccoid & Coccoid \\
\hline Cell size & $0.4 \times 1.0$ & $\begin{array}{c}0.6-0.8 \times \\
1.8-3.6\end{array}$ & $\begin{array}{c}0.5-0.6 \times \\
2.8-11.0\end{array}$ & $3.0-10.0$ & $\begin{array}{c}0.4-1.0 \times \\
3.0-10.0\end{array}$ & $\begin{array}{c}0.7-1.0 \times \\
4.0-13.0\end{array}$ & $0.1-0.3$ & $\begin{array}{c}1.1-1.5 \times \\
1.1-1.7\end{array}$ & $1.2-1.6$ & $1.5-2.0$ \\
\hline Motility & - & + & - & - & + & - & - & - & - & + \\
\hline Colony pigmentation & Light red & Red & Red & Deep red & Light red & Pale red & Cream & Pale red & Light red & $\begin{array}{l}\text { Red or light } \\
\text { pink }\end{array}$ \\
\hline Cells lyse in distilled water & + & + & + & + & + & + & + & - & - & - \\
\hline $\mathrm{NaCl}$ range, \% (w/v) (optimum) & $\begin{array}{l}10-30 \\
(15-20)\end{array}$ & $\begin{array}{c}10-30 \\
(18)\end{array}$ & $\begin{array}{c}10-30 \\
(18)\end{array}$ & $\begin{array}{l}12-30 \\
(20-29)\end{array}$ & $>10(17.5-20)$ & $12-25(17.5-20)$ & $\begin{array}{l}11-32 \\
(17-20)\end{array}$ & $\begin{array}{l}10-30 \\
(20-25)\end{array}$ & $\begin{array}{l}15-29 \\
(20)\end{array}$ & $>12(15-20)$ \\
\hline $\mathrm{MgCl}_{2}$ requirement & - & + & - & ND & - & - & - & - & - & + \\
\hline Temperature range (optimum) & $\begin{array}{l}17-50 \\
(37-45)\end{array}$ & $\begin{array}{l}30-61 \\
(40-45)\end{array}$ & $\begin{array}{c}30-56 \\
(41-45)\end{array}$ & $\begin{array}{l}35-55 \\
(45-55)\end{array}$ & $24-58(42-45)$ & $25-60(50)$ & $\begin{array}{c}25-50 \\
(37-45)\end{array}$ & $20-55(42)$ & $\begin{array}{c}25-50 \\
(37)\end{array}$ & $20-55(45)$ \\
\hline pH range (optimum) & $\begin{array}{c}6.5-8.5 \\
(7.0-7.5)\end{array}$ & $\begin{array}{c}6.5-9.0 \\
(7.0)\end{array}$ & $\begin{array}{c}6.5-9.0 \\
(7.0-7.5)\end{array}$ & $\begin{array}{l}6.0-9.0 \\
(6.5-8.2)\end{array}$ & $6.5-8.5(7.5)$ & $6.5-8.2(7.0-7.5)$ & $6.0-8.0(7.0)$ & $\begin{array}{l}6.0-9.5 \\
(7.5-8.0)\end{array}$ & $\begin{array}{l}6.0-9.0 \\
(7.0-8.0)\end{array}$ & ND \\
\hline
\end{tabular}

Anaerobic growth in presence of:

$\begin{array}{lccc}\text { Nitrate } & + & - & - \\ \text { L-arginine } & \text { ND } & - & - \\ \text { Oxidase } & - & + & + \\ \text { Catalase } & + & + & + \\ \text { Nitrate reduction to nitrite } & - & + & - \\ \text { Gas from nitrate } & \text { ND } & \text { ND } & \text { ND } \\ \text { Indole production } & + & - & + \\ \mathrm{H}_{2} S \text { production } & \text { ND } & + & +\end{array}$

$\begin{array}{ccccccc}\mathrm{ND} & + & - & - & - & - & \mathrm{ND} \\ \mathrm{ND} & \mathrm{ND} & - & - & - & - & \mathrm{ND} \\ - & + & + & + & - & + & - \\ + & + & + & + & + & + & \mathrm{ND} \\ + & + & - & \mathrm{ND} & - & - & + \\ \mathrm{ND} & - & - & - & - & - & - \\ + & - & - & + & - & - & - \\ + & + & + & & & \end{array}$


TABLE 2 | (Continued)

\begin{tabular}{|c|c|c|c|c|c|c|c|c|c|c|}
\hline Characteristics & $\begin{array}{c}\text { Htg. } \\
\text { jeotgali }\end{array}$ & $\begin{array}{c}\text { Htg. } \\
\text { limicola }^{\mathrm{j}}\end{array}$ & $\begin{array}{c}\text { Htg. } \\
\text { longa }\end{array}$ & $\begin{array}{c}\text { Htg. } \\
\text { mahiir }\end{array}$ & $\begin{array}{c}\text { Htg. } \\
\text { saccharevitans }\end{array}$ & $\begin{array}{l}\text { Htg. } \\
\text { thermotolerans }^{\mathrm{m}}\end{array}$ & $\begin{array}{l}\text { Hpg. } \\
\text { salifodinae }^{n}\end{array}$ & $\begin{array}{c}\text { Htg. } \\
\text { salifodinae }^{\circ}\end{array}$ & $\begin{array}{l}\text { Htg. } \\
\text { salina }^{p}\end{array}$ & $\begin{array}{c}\text { Htg. } \\
\text { turkmenicaq }\end{array}$ \\
\hline \multicolumn{11}{|l|}{ Hydrolysis of: } \\
\hline Starch & - & - & - & - & - & - & - & - & - & - \\
\hline Casein & + & - & - & - & - & - & - & ND & - & ND \\
\hline Gelatin & - & - & - & - & - & + & - & - & - & - \\
\hline Tween 80 & + & - & - & + & + & + & - & - & - & - \\
\hline \multicolumn{11}{|c|}{ Utilization as sole carbon and energy source of: } \\
\hline Acetate & + & + & + & ND & + & ND & + & + & + & ND \\
\hline D-Glucose & - & - & + & + & - & - & + & + & + & + \\
\hline D-Fructose & + & - & - & + & - & - & - & - & + & + \\
\hline D-Galactose & ND & - & - & ND & - & - & - & + & + & ND \\
\hline D-Mannose & ND & - & - & ND & - & - & + & + & + & + \\
\hline D-Ribose & ND & - & - & - & - & - & - & - & - & + \\
\hline D-Xylose & ND & - & - & - & - & - & - & - & + & - \\
\hline Sucrose & - & - & + & + & - & - & ND & + & - & + \\
\hline Maltose & ND & - & + & ND & - & - & - & - & + & ND \\
\hline Lactose & + & - & - & + & - & - & - & + & + & + \\
\hline Glycerol & ND & ND & ND & ND & + & - & - & + & + & ND \\
\hline Sorbitol & ND & - & - & ND & - & ND & + & - & - & ND \\
\hline D-Mannitol & ND & - & - & ND & - & - & - & - & - & ND \\
\hline \multicolumn{11}{|c|}{ Acid production from: } \\
\hline D-Mannose & ND & - & - & - & - & - & + & - & - & + \\
\hline D-Glucose & ND & - & + & - & - & - & + & - & - & + \\
\hline \multicolumn{11}{|l|}{ Lipids: } \\
\hline Major polar lipids & $\begin{array}{c}\text { PG, } \\
\text { PGP-Me }\end{array}$ & $\begin{array}{c}\text { PG, } \\
\text { PGP-Me }\end{array}$ & $\begin{array}{c}\text { PG, } \\
\text { PGP-Me }\end{array}$ & $\begin{array}{c}\text { PG, } \\
\text { PGP-Me }\end{array}$ & PG, PGP-Me & PG, PGP-Me & PG, PGP-Me & PG, PGP-Me & $\begin{array}{c}\text { PG, } \\
\text { PGP-Me }\end{array}$ & PG, PGP-Me \\
\hline Major glycolipids & $\mathrm{S}_{2}-\mathrm{DGD}-1$ & $\mathrm{~S}_{2}$-DGD-1 & $\mathrm{S}_{2}-\mathrm{DGD}-1$ & $\mathrm{~S}_{2}$-DGD-1 & $\mathrm{S}_{2}-\mathrm{DGD}-1$ & $\mathrm{~S}_{2}-\mathrm{DGD}-1$ & $\mathrm{~S}_{2}-\mathrm{DGD}-1$ & $\begin{array}{l}\text { S-DGD-1, } \\
\text { S }_{2}-D G D-1\end{array}$ & $\begin{array}{l}\text { S-DGD-1, } \\
\text { S }_{2} \text {-DGD-1 }\end{array}$ & $\mathrm{S}_{2}-\mathrm{DGD}-1$ \\
\hline Presence of PGS & - & - & - & - & - & - & - & - & - & - \\
\hline
\end{tabular}


TABLE 2 | (Continued)

\begin{tabular}{|c|c|c|c|c|c|c|c|c|}
\hline Characteristics & Nrr. aibiense ${ }^{r}$ & $\begin{array}{c}\text { Nrr. } \\
\text { bangense }\end{array}$ & $\begin{array}{c}\text { Nrr. } \\
\text { halophilum }^{\mathrm{t}}\end{array}$ & $\begin{array}{c}\text { Nrr. } \\
\text { sediminis }^{\mathrm{u}}\end{array}$ & $\begin{array}{c}\text { Nrr. } \\
\text { sulfidifaciens }{ }^{\vee}\end{array}$ & $\begin{array}{c}\text { Nrr. } \\
\text { texcoconensew }\end{array}$ & $\begin{array}{c}\text { Nrr. } \\
\text { tibetense }\end{array}$ & $\begin{array}{c}\text { Htg. } \\
\text { daqingensis } \\
\end{array}$ \\
\hline Morphology & Rods & Pleomorphic & Pleomorphic & Pleomorphic & Pleomorphic & Pleomorphic & Pleomorphic & Coccoid \\
\hline Cell size & $\begin{array}{c}0.8-1.0 \times \\
1.4-3.6\end{array}$ & ND & ND & $\begin{array}{c}0.8-1.0 \times \\
4.0-6.0\end{array}$ & ND & $\begin{array}{c}0.8-1.0 \times \\
1.0-5.0\end{array}$ & ND & $0.8-1.3$ \\
\hline Motility & + & - & + & - & + & - & - & - \\
\hline Colony pigmentation & Red & Red & Red & Pink & Red & Pink-red & Red & Orange \\
\hline Cells lyse in distilled water & + & + & + & + & ND & + & + & - \\
\hline $\mathrm{NaCl}$ range, \% (w/v) (optimum) & $12-25(15-18)$ & $12-25(22.5)$ & $8-28(15-18)$ & $15-29(20)$ & $12-28(18)$ & $10-25(15-20)$ & $12-30(20)$ & $10-32(12-15)$ \\
\hline $\mathrm{MgCl}_{2}$ requirement & - & ND & - & - & + & - & ND & ND \\
\hline Temperature range (optimum) & $20-50(45)$ & $25-55(45)$ & 25-42 (37) & $25-50(37)$ & $20-55(44-47)$ & $25-45(37)$ & $25-55(45)$ & 20-50 (35) \\
\hline pH range (optimum) & $6.5-9.5(8.0)$ & $8.0-11.0(9.5)$ & $\begin{array}{l}5.5-9.5 \\
(7.0-7.5)\end{array}$ & $8.0-11.0(9.0)$ & $\begin{array}{l}8.0-10.0 \\
(8.7-9.2)\end{array}$ & $8.0-10.5(9.0)$ & $8.5-11.0(9.0)$ & $8.0-10.5(10.0)$ \\
\hline \multicolumn{9}{|c|}{ Anaerobic growth in presence of: } \\
\hline Nitrate & - & - & + & - & - & - & - & - \\
\hline L-arginine & - & ND & - & - & - & - & ND & - \\
\hline Oxidase & + & + & + & + & + & - & + & - \\
\hline Catalase & + & + & + & + & + & + & + & + \\
\hline Nitrate reduction to nitrite & + & - & + & + & + & - & - & - \\
\hline Gas from nitrate & + & - & v & - & + & - & - & ND \\
\hline Indole production & + & + & + & - & + & - & + & - \\
\hline $\mathrm{H}_{2} \mathrm{~S}$ production & - & - & v & - & + & - & - & + \\
\hline \multicolumn{9}{|l|}{ Hydrolysis of: } \\
\hline Starch & - & - & + & - & - & - & - & - \\
\hline Casein & - & - & v & - & - & - & - & - \\
\hline Gelatin & - & - & v & - & - & - & + & - \\
\hline Tween 80 & - & - & $v$ & + & - & - & - & + \\
\hline \multicolumn{9}{|c|}{ Utilization as sole carbon and energy source of: } \\
\hline Acetate & ND & + & - & - & + & ND & + & + \\
\hline D-Glucose & + & + & v & + & + & + & + & - \\
\hline
\end{tabular}


TABLE 2 | (Continued)

\begin{tabular}{|c|c|c|c|c|c|c|c|c|}
\hline Characteristics & Nrr. aibienser & $\begin{array}{c}\text { Nrr. } \\
\text { bangense }\end{array}$ & $\begin{array}{c}\text { Nrr. } \\
\text { halophilum }\end{array}$ & $\begin{array}{c}\text { Nrr. } \\
\text { sediminis }^{\mathrm{u}}\end{array}$ & $\begin{array}{c}\text { Nrr. } \\
\text { sulfidifaciens }^{v}\end{array}$ & $\begin{array}{c}\text { Nrr. } \\
\text { texcoconense }\end{array}$ & $\begin{array}{c}\text { Nrr. } \\
\text { tibetense }\end{array}$ & $\begin{array}{c}\text { Htg. } \\
\text { daqingensis }\end{array}$ \\
\hline D-Fructose & - & + & - & + & - & ND & + & - \\
\hline D-Galactose & + & - & + & - & - & ND & - & - \\
\hline D-Mannose & - & - & $v$ & + & - & + & - & - \\
\hline D-Ribose & - & ND & - & - & - & ND & ND & - \\
\hline D-Xylose & - & - & - & + & - & ND & - & - \\
\hline Sucrose & + & + & + & ND & + & + & + & - \\
\hline Maltose & + & + & - & - & + & - & + & - \\
\hline Lactose & - & + & - & - & - & + & + & - \\
\hline Glycerol & ND & ND & + & - & + & ND & ND & + \\
\hline Sorbitol & - & ND & - & - & - & ND & ND & - \\
\hline D-Mannitol & - & - & - & - & - & - & - & - \\
\hline \multicolumn{9}{|c|}{ Acid production from: } \\
\hline D-Mannose & - & ND & + & ND & ND & ND & ND & - \\
\hline D-Glucose & + & ND & + & ND & ND & + & ND & - \\
\hline \multicolumn{9}{|l|}{ Lipids: } \\
\hline Major polar lipids & PG, PGP-Me & PG, PGP-Me & PG, PGP-Me & PG, PGP-Me & PG, PGP-Me & PG, PGP-Me & PG, PGP-Me & PG, PGP-Me \\
\hline Major glycolipids & $\begin{array}{l}\mathrm{S}_{2}-\mathrm{DGD}-1 \\
\text { TGD-1 }\end{array}$ & None & $\begin{array}{c}\mathrm{S}_{2}-\mathrm{DGD}-1 \\
\text { TGD-1 }\end{array}$ & None & None & None & None & $\mathrm{S}_{2}-\mathrm{DGD}-1$ \\
\hline Presence of PGS & - & - & - & - & - & - & - & - \\
\hline
\end{tabular}

+ , positive; -, negative; ND, not determined; \pm , doubtful; v, variable. Species that should be regarded as member of the genera Natrinema, Haloterrigena, or Natronorubrum are marked in light orange, light blue, and light green, respectively.

a Data from Xu et al. (2005b).

${ }^{b}$ Data from Castillo et al. (2006).

${ }^{\circ}$ Data from Tapingkae et al. (2008).

${ }^{d}$ Data from McGenity et al. (1998).

eData from Albuquerque et al. (2012).

${ }^{f}$ Data from Rasooli et al. (2017).

${ }^{9}$ Data from Xin et al. (2000).

${ }^{\text {h}}$ Data from Romano et al. (2007).

'Data from Roh et al. (2009).

'Data from Cui et al. (2006b).

${ }^{k}$ Data from Ding et al. (2017).

Data from Xu et al. (2005a).

m Data from Montalvo-Rodríguez et al. (2000).

${ }^{n}$ Data from Zhang et al. (2013).

${ }^{\circ}$ Data from Chen et al. (2019).

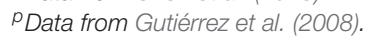

a Data from Zvyagintseva and Tarasov (1987) and Ventosa et al. (1999).

'Data from Cui et al. (2006a).

${ }^{s}$ Data from Xu et al. (1999).

'Data from Tao et al. (2020).

"Data from Gutiérrez et al. (2010).

Data from Cui et al. (2007).

wData from Ruiz-Romero et al. (2013).

${ }^{x}$ Data from Wang et al. (2010). 
differences in the polar lipid composition between the species of the genera Natrinema and Haloterrigena -with Natrinema species harboring PGS but not $\mathrm{S}_{2}$-DGD-1 (McGenity et al., 1998; Xin et al., 2000; Xu et al., 2005b; Tapingkae et al., 2008), while Haloterrigena representatives containing $\mathrm{S}_{2}$ DGD-1 and lacking PGS (Montalvo-Rodríguez et al., 2000; $\mathrm{Xu}$ et al., 2005a; Cui et al., 2006b; Roh et al., 2009; Ding et al., 2017)-, we observed that minor polar lipid profiles are not genus-specific. For example, Natrinema ejinorense and Natrinema soli possessed $\mathrm{S}_{2}$-DGD-1 and lacked PGS, and Natrinema salaciae contained $\mathrm{S}_{2}$-DGD-1 (characteristic profiles of Haloterrigena species). On the contrary, Haloterrigena hispanica did not hold $\mathrm{S}_{2}$-DGD-1 (typical profile of Natrinema species). Therefore, those differences in minor polar lipid composition cannot be regarded as phenotypic incoherence within the Natrinema/Haloterrigena/Halopiger salifodinae cluster, whose species should be merged into the single genus Natrinema.

With respect to genera differentiation, the genuine genus Haloterrigena (Haloterrigena turkmenica, Haloterrigena salifodinae, and Haloterrigena salina) can be distinguished from the now expanded genus Natrinema (Natrinema/Haloterrigena/Halopiger salifodinae group) by the resistance to cell lysis in distilled water of the former but not of the latter. Likewise, members of the genus Natronorubrum (now also including the species Haloterrigena daqingensis) are haloalkalophiles, in contrast to their Haloterrigena and Natrinema counterparts which better thrive at almost neutral $\mathrm{pH}$ values (Table 2).

At the species level, phenotypic features can also shed light on uncertain taxa. This is the case of the cluster Natrinema pellirubrum/Haloterrigena jeotgali/Haloterrigena thermotolerans and the cluster Natrinema ejinorense/Haloterrigena longa, for which OGRI values fell in the fuzzy zone and synteny analysis agreed with the possibility of merging the species within each cluster. A careful inspection of the phenotypic characteristics of Natrinema pellirubrum, Haloterrigena jeotgali, and Haloterrigena thermotolerans demonstrated a similar profile for the two latter, whereas the former showed significant differences as to be considered as a separated species, such as the cell motility, the absence of $S_{2}$-DGD-1 glycolipid and the presence of PGS (Table 2). On the contrary, phenotypic profile for the species Natrinema ejinorense and Haloterrigena longa was quite similar, with only minor strain-specific differences (Table 2), thus supporting the unification of both taxa into a single species.

\section{Taxonomic Consequences}

After having completed detailed phylogenomic, genomic and phenotypic comparative analyses in the family Natrialbaceae, and more specifically in the genera Natrinema and Haloterrigena, we have demonstrated that the species Haloterrigena jeotgali and Natrinema ejinorense should be considered as later heterotypic synonyms of the species Haloterrigena thermotolerans and Haloterrigena longa, respectively, according to Rule 23a of the International Code of Nomenclature of Prokaryotes (Parker et al., 2019). Additionally, the species Haloterrigena hispanica, Haloterrigena limicola, Haloterrigena longa/Natrinema ejinorense, Haloterrigena mahii, Haloterrigena saccharevitans, Haloterrigena thermotolerans/Haloterrigena jeotgali, and Halopiger salifodinae should be transferred to the genus Natrinema, as Natrinema hispanicum, Natrinema limicola, Natrinema longum, Natrinema mahii, Natrinema saccharevitans, Natrinema thermotolerans, and Natrinema salifodinae, respectively. On the contrary, the species Haloterrigena turkmenica, Haloterrigena salifodinae, and Haloterrigena salina will remain as the only representative species of the genus Haloterrigena. Besides, the species Haloterrigena daqingensis should be reclassified as a member of the genus Natronorubrum, as Natronorubrum daqingense.

With regards to non-type or unnamed strains, our study indicates that the strains Natrinema sp. J7-1, Natrinema sp. J7-2, and Haloterrigena turkmenica WANU15 should be renamed as Natrinema gari J7-1, Natrinema gari J7-2, and Natronolimnohabitans innermongolicus WANU15, respectively, although it is worth mentioning that the genome sequence of Haloterrigena turkmenica WANU15 has been identified as contaminated in a previous study (Lee et al., 2017). Moreover, the strains Haloterrigena hispanica CDM_1 and Haloterrigena hispanica CDM_6 should not be longer affiliated to the species Haloterrigena (Natrinema) hispanica and, thus, they should be referred as Natrinema sp. CDM_1 and Natrinema sp. CDM_6, respectively.

On the basis of these data, we propose the following taxonomic re-arrangements.

\section{Description of Natrinema hispanicum comb. nov.}

Natrinema hispanicum (his.pa'ni.cum. L. neut. adj. hispanicum of Hispania, from where the organism was originally isolated)

Basonym: Haloterrigena hispanica Romano et al., 2007, 1501.

The description is identical to that of Haloterrigena hispanica as given previously (Romano et al., 2007) with the following amendments: the $\mathrm{G}+\mathrm{C}$ content of the type strain genome is $60.7 \mathrm{~mol} \%$, its approximate size $4.26 \mathrm{Mb}$, and its GenBank Assembly accession number is GCA_004217335.1.

The type strain is $\mathrm{FP}^{\mathrm{T}}\left(=\right.$ ATCC BAA- $\left.1310^{\mathrm{T}}=\mathrm{DSM} 18328^{\mathrm{T}}\right)$.

Description of Natrinema limicola comb. nov.

Natrinema limicola (li.mi'co.la. L. masc. n. limus mud; L. suff. - cola from L. masc. or fem. n. incola dweller; N.L. n. limicola mud-dweller)

\section{Basonym: Haloterrigena limicola Cui et al., 2006b, 1839.}

The description is identical to that of Haloterrigena limicola as given previously (Cui et al., 2006b) with the following amendments: the $\mathrm{G}+\mathrm{C}$ content of the type strain genome is $61.8 \mathrm{~mol} \%$, its approximate size $3.52 \mathrm{Mb}$, and its GenBank Assembly accession number is GCA_000337475.1.

The type strain is AX-7 ${ }^{\mathrm{T}}\left(=\mathrm{CGMCC} 1.5333^{\mathrm{T}}=\mathrm{JCM} 13563^{\mathrm{T}}\right)$.

Description of Natrinema longum comb. nov.

Natrinema longum (lon'gum. L. neut. adj. longum long, referring to the production of long rods in liquid medium)

Basonym: Haloterrigena longa Cui et al., 2006b, 1838. 
The description is identical to that of Haloterrigena longa as given previously (Cui et al., 2006b) with the amendments as follows. Cells are rod-shaped or pleomorphic $(0.5-2.0 \times 1.5-$ $11.0 \mu \mathrm{m})$. Aerobic growth occurs at $\mathrm{pH} 6.0-9.0$ and $25-56^{\circ} \mathrm{C}$. Optimal $\mathrm{NaCl}$ concentration and temperature for growth are 18 $20 \%(\mathrm{w} / \mathrm{v})$ and $37-45^{\circ} \mathrm{C}$, respectively. Nitrate reduction to nitrite is variable. Indole and $\mathrm{H}_{2} \mathrm{~S}$ formation are variable. Hydrolysis of starch, gelatin and Tween 80 is variable. Assimilation of fructose as carbon and energy sources is variable. Acid production from glucose and sucrose is variable. Phosphatidylglycerol sulfate polar lipid is absent or below detection limit. The DNA G $+\mathrm{C}$ content is $61.8-63.9 \mathrm{~mol} \%$ (genome).

The type strain is $\mathrm{ABH} 32^{\mathrm{T}}$ (= CGMCC $1.5334^{\mathrm{T}}=\mathrm{JCM}$ $\left.13562^{\mathrm{T}}\right)$. The $\mathrm{G}+\mathrm{C}$ content of the type strain genome is $61.8 \mathrm{~mol} \%$, its approximate size $3.52 \mathrm{Mb}$, and its GenBank Assembly accession number is GCA_020105915.1.

Natrinema ejinorense EJ-57 (= CECT 7144 = CGMCC $1.6202=$ DSM $18194=$ JCM 13890) is an additional strain of Natrinema longa. The $\mathrm{G}+\mathrm{C}$ content of this reference strain genome is $63.9 \mathrm{~mol} \%$, its approximate size $4.48 \mathrm{Mb}$, and its GenBank Assembly accession number is GCA_002494345.1.

Description of Natrinema mahii comb. nov.

Natrinema mahii (mah'i.i. N.L. gen. n. mahii of Mah, in honor of R.A. Mah at UCLA for his noteworthy research in the areas of archaea isolation and classification, and also for initiating the solar saltern sampling in the original description)

\section{Basonym: Haloterrigena mahii Ding et al., 2017, 1337.}

The description is identical to that of Haloterrigena mahii as given previously (Ding et al., 2017) with the following amendments: the $\mathrm{G}+\mathrm{C}$ content of the type strain genome is $65.1 \mathrm{~mol} \%$, its approximate size $3.79 \mathrm{Mb}$, and its GenBank Assembly accession number is GCA_000690595.2.

The type strain is $\mathrm{H}_{13}^{\mathrm{T}}\left(=\mathrm{BCRC} 910151^{\mathrm{T}}=\operatorname{NBRC} 111885^{\mathrm{T}}\right)$.

Description of Natrinema saccharevitans comb. nov.

Natrinema saccharevitans (sac.char.e.vi'tans. L. neut. n. saccharon, $-i$ a kind of sugar; L. pres. part. evitans shunning, avoiding; N.L. part. adj. saccharevitans sugar-avoiding, because it uses very few sugars)

Basonym: Haloterrigena saccharevitans Xu et al., 2005a, 2541.

The description is identical to that of Haloterrigena saccharevitans as given previously (Xu et al., 2005a) with the following amendments: the $\mathrm{G}+\mathrm{C}$ content of the type strain genome is $65.3 \mathrm{~mol} \%$, its approximate size $3.98 \mathrm{Mb}$, and its GenBank Assembly accession number is GCA_001953745.1.

The type strain is $\mathrm{AB} 14^{\mathrm{T}}\left(=\right.$ AS $\left.1.3730^{\mathrm{T}}=\mathrm{JCM} 12889^{\mathrm{T}}\right)$.

Description of Natrinema thermotolerans comb. nov.

Natrinema thermotolerans (ther.mo.to'le.rans. Gr. fem. n. therme heat; L. pres. part. tolerans tolerating; N.L. part. adj. thermotolerans heat-tolerant)

Basonym: Haloterrigena thermotolerans Montalvo-Rodríguez et al., 2000, 1070 .
The description is identical to that of Haloterrigena thermotolerans as given previously (Montalvo-Rodríguez et al., 2000) with the amendments as follows. Cells are 0.4$1.0 \times 1.0-13.0 \mu \mathrm{m}$. Aerobic growth occurs in the presence of $10-30 \%(\mathrm{w} / \mathrm{v}) \mathrm{NaCl}, \mathrm{pH} 6.5-8.5$ and $17-60^{\circ} \mathrm{C}$. Optimal $\mathrm{NaCl}$ concentration and temperature for growth are $15-20 \%(\mathrm{w} / \mathrm{v})$ and $37-50^{\circ} \mathrm{C}$, respectively. Anaerobic growth in the presence of nitrate is variable. Oxidase activity, reduction of nitrate to nitrite and indole formation are variable. Hydrolysis of casein and gelatin is variable. Assimilation of fructose and lactose as carbon and energy sources is variable. The DNA G $+\mathrm{C}$ content is $65.0-65.4 \mathrm{~mol} \%$ (genome).

The type strain is PR5 ${ }^{\mathrm{T}}\left(=\right.$ ATCC $\left.700275^{\mathrm{T}}=\mathrm{DSM} 11552^{\mathrm{T}}\right)$. The $\mathrm{G}+\mathrm{C}$ content of the type strain genome is $65.4 \mathrm{~mol} \%$, its approximate size $3.90 \mathrm{Mb}$, and its GenBank Assembly accession number is GCA_000337115.1.

Haloterrigena jeotgali A29 (= CECT $7218=$ DSM $18794=$ JCM $14585=$ KCTC 4020) is an additional strain of Natrinema thermotolerans. The $\mathrm{G}+\mathrm{C}$ content of this reference strain genome is $65.0 \mathrm{~mol} \%$, its approximate size $4.90 \mathrm{Mb}$, and its GenBank Assembly accession number is GCA_004799625.1.

Description of Natrinema salifodinae comb. nov.

Natrinema salifodinae (sa.li.fo.di'nae. N.L. gen. fem. n. salifodinae of a saltpit, salt mine)

Basonym: Halopiger salifodinae Zhang et al., 2013, 3565.

The description is identical to that of Halopiger salifodinae as given previously (Zhang et al., 2013) with the following amendments: the $\mathrm{G}+\mathrm{C}$ content of the type strain genome is $65.4 \mathrm{~mol} \%$, its approximate size $4.27 \mathrm{Mb}$, and its GenBank Assembly accession number is GCA_900110455.1.

The type strain is KCY07-B2 ${ }^{\mathrm{T}}$ (= CGMCC $1.12284^{\mathrm{T}}=\mathrm{DSM}$ $26231^{\mathrm{T}}=$ JCM $18547^{\mathrm{T}}$ ).

\section{Description of Natronorubrum daqingense comb. nov.}

Natronorubrum daqingense (da.qing.en'se. N.L. neut. adj. daqingense pertaining to Daqing, north-east China, where the type strain was isolated)

Basonym: Haloterrigena daqingensis Wang et al., 2010, 2270.

The description is identical to that of Haloterrigena daqingensis as given previously (Wang et al., 2010) with the following amendments: the $\mathrm{G}+\mathrm{C}$ content of the type strain genome is $61.3-61.4 \mathrm{~mol} \%$, its approximate size 3.83 $3.84 \mathrm{Mb}$, and its GenBank Assembly accession numbers are GCA_900156445.1 and GCA_001971705.1.

The type strain is $\mathrm{JX}_{313^{\mathrm{T}}}\left(=\right.$ CGMCC $1.8909^{\mathrm{T}}=\mathrm{NBRC}$ $\left.105739^{\mathrm{T}}\right)$.

\section{Emended description of the genus Natrinema}

Natrinema (Na.tri.ne'ma. N.L. n. natrium sodium; Gr. neut. n. nema a thread; N.L. neut. n. Natrinema the sodium thread, referring to the high sodium ion requirement, and the cell shape)

Cells are rods, coccoid or pleomorphic. Cells lyse at low $\mathrm{NaCl}$ concentration $(<1.0 \mathrm{M})$. Colonies are red, light 
orange-red, pale orange-red, or cream pigmented. Chemoorganotroph. Some species are strict aerobes, whereas others show anaerobic growth with nitrate. Catalase positive. Grows on a wide range of substrates, including single and complex carbon sources. Extremely halophilic, requiring at least 9-10\% $(\mathrm{w} / \mathrm{v}) \mathrm{NaCl}$ for growth, with optimum at $15-29 \%(\mathrm{w} / \mathrm{v}) \mathrm{NaCl}$. Grows at $\mathrm{pH}$ values of 5.5-9.0, with optimum $\mathrm{pH}$ at 6.0-8.2. Temperature supporting growth ranges from 17 to $61^{\circ} \mathrm{C}$, with optimum at $30-55^{\circ} \mathrm{C}$. Possesses $\mathrm{C}_{20} \mathrm{C}_{20}$ and $\mathrm{C}_{20} \mathrm{C}_{25}$ diether core lipids. The major polar lipids consist of phosphatidylglycerol and phosphatidylglycerol-phosphate-methyl ester, with some species also containing phosphatidylglycerol sulfate. Most species possess the glycolipid $\mathrm{S}_{2}$-DGD-1, while some species possess S-DGD-1 or unidentified glycolipids. The DNA G $+\mathrm{C}$ content is in the range of $60.7-65.4 \mathrm{~mol} \%$ (genome). The genus is a member of the family Natrialbaceae, order Natrialbales, class Halobacteria. The recommended three-letter abbreviation is Nnm. The type species is Natrinema pellirubrum.

\section{Emended description of the genus Haloterrigena}

Haloterrigena (Ha.lo.ter.ri'ge.na. Gr. n. hals halos the sea, salt; L. fem. adj. terrigena born from the earth; N.L. fem. n. Haloterrigena salt (-requiring) and born from the earth).

Cells are Gram-strain-negative, coccoid, or oval-shaped, and 1.1-2.0 $\mu \mathrm{m}$ in size. Colonies are colored light red or light pink due to the presence of bacterioruberin carotenoids. Cells are non-motile or motile and aerobic. Catalase-positive and oxidase-variable. Extremely halophilic, with growth occurring in media containing $10-30 \%(\mathrm{w} / \mathrm{v}) \mathrm{NaCl}$, with optimum at 15-25\% (w/v) NaCl. Cells lyse in distilled water. Species may require or not magnesium to grow. Grows at $\mathrm{pH}$ values of $6.0-9.5$, with optimum $\mathrm{pH}$ at 7.0-8.0. Temperature supporting growth ranges from 20 to $55^{\circ} \mathrm{C}$, with optimum at $37-45^{\circ} \mathrm{C}$. Some species reduce nitrate to nitrite but they do not form gas from nitrate. Indole formation and $\mathrm{H}_{2} \mathrm{~S}$ production are negative. Hydrolysis of starch, gelatin and Tween 80 is negative. Chemo-organotrophic. All species use sugars, some of them with the production of acids. The major polar lipids are $\mathrm{C}_{20} \mathrm{C}_{20}$ and $\mathrm{C}_{20} \mathrm{C}_{25}$ glycerol diether derivatives of phosphatidylglycerol and phosphatidylglycerol-phosphatemethyl ester as well as the glycolipid $S_{2}$-DGD-1. Some species may also contain the glycolipid S-DGD-1. Phosphatidylglycerol sulfate is absent. The DNA G $+\mathrm{C}$ content is between 64.5 and $65.4 \mathrm{~mol} \%$ (genome). The genus is a member of the family Natrialbaceae, order Natrialbales, class Halobacteria. The recommended three-letter abbreviation is Htg. The type species is Haloterrigena turkmenica.

\section{Emended description of the genus Natronorubrum}

Natronorubrum (Na.tro.no.ru'brum. Gr. n. natron derived from Arabic natrun soda (sodium carbonate); L. neut. adj. rubrum red; N.L. neut. n. Natronorubrum the red of soda).

Cells are Gram-strain-negative, rods, coccoid or pleomorphic (flat, triangular, square, disc and other polygonal shapes). Colonies are red, pink, or orange pigmented. Cells are nonmotile or motile, aerobic or facultative anaerobic. Catalasepositive and oxidase-variable. Extremely halophilic, with growth occurring in media containing $8-32 \%$ (w/v) $\mathrm{NaCl}$, with optimum at $12-22.5 \%(\mathrm{w} / \mathrm{v}) \mathrm{NaCl}$. Cells from most species are lysed in distilled water, but others are not. Alkaliphilic or neutrophilic, growing at $\mathrm{pH}$ values of 5.5-11.0, with optimum $\mathrm{pH}$ at 7.0-10.0. Temperature supporting growth ranges from 20 to $55^{\circ} \mathrm{C}$, with optimum at $35-47^{\circ} \mathrm{C}$. Chemoorganotrophic. Many substrates are utilized, sometimes with acid production. The major polar lipids are $\mathrm{C}_{20} \mathrm{C}_{20}$ and $\mathrm{C}_{20} \mathrm{C}_{25}$ derivatives of phosphatidylglycerol and phosphatidylglycerolphosphate-methyl ester. Phosphatidylglycerol sulfate is absent. Cells may also contain $S_{2}$-DGD-1, TGD-1 and other unidentified glycolipids. The DNA G $+\mathrm{C}$ content is in the range of 60.4-63.6 mol\% (genome). The genus is a member of the family Natrialbaceae, order Natrialbales, class Halobacteria. The recommended three-letter abbreviation is Nrr. The type species is Natronorubrum bangense.

\section{DATA AVAILABILITY STATEMENT}

The datasets presented in this study can be found in online repositories. The names of the repository/repositories and accession number(s) can be found in the article/ Supplementary Material.

\section{AUTHOR CONTRIBUTIONS}

RRH, HM, MK, YS, and AV: conceptualization, investigation, writing - review and editing. RRH, HM, and YS: methodology, formal analysis. RRH, HM, and MK: validation. HM, MK, YS, and $\mathrm{AV}$ : resources, project administration, and funding acquisition. RRH and HM: data curation, writing - original draft preparation, and visualization. MK, YS, and AV: supervision. All authors have read and agreed to the published version of the manuscript.

\section{FUNDING}

This research was funded by Junta de Andalucía, Spain (grants US-1263771 [US/JUNTA/FEDER, UE], P20_01066 and BIO-213, which included FEDER funds), and FEDER/Spanish Ministry of Science and Innovation-State Research Agency (projects CGL2017-83385-P and PID2020-118136GB-I00).

\section{ACKNOWLEDGMENTS}

We wish to thank the reviewers for their generous and meaningful efforts.

\section{SUPPLEMENTARY MATERIAL}

The Supplementary Material for this article can be found online at: https://www.frontiersin.org/articles/10.3389/fmicb. 2021.740909/full\#supplementary-material 


\section{REFERENCES}

Albuquerque, L., Taborda, M., La Cono, V., Yakimov, M., and da Costa, M. S. (2012). Natrinema salaciae sp. nov., a halophilic archaeon isolated from the deep, hypersaline anoxic Lake Medee in the Eastern Mediterranean Sea. Syst. Appl. Microbiol. 35, 368-373. doi: 10.1016/j.syapm.2012.06.005

Auch, A. F., von Jan, M., Klenk, H.-P., and Göker, M. (2010). Digital DNA-DNA hybridization for microbial species delineation by means of genome-to-genome sequence comparison. Stand. Genomic Sci. 2, 117-134. doi: 10.4056/sigs.531120

Bankevich, A., Nurk, S., Antipov, D., Gurevich, A. A., Dvorkin, M., Kulikov, A. S., et al. (2012). SPAdes: a new genome assembly algorithm and its applications to single-cell sequencing. J. Comput. Biol. 19, 455-477. doi: 10.1089/cmb. 2012.0021

Barco, R. A., Garrity, G. M., Scott, J. J., Amend, J. P., Nealson, K. H., and Emerson, D. (2020). A genus definition for Bacteria and Archaea based on a standard genome relatedness index. mBio 11:e02475-19. doi: 10.1128/mBio.02475-19

Bhutkar, A., Russo, S., Smith, T. F., and Gelbart, W. M. (2006). Techniques for multi-genome synteny analysis to overcome assembly limitations. Genome Inform. 17, 152-161. doi: 10.11234/gi1990.17.2_152

Borriss, R., Rueckert, C., Blom, J., Bezuidt, O., Reva, O., and Klenk, H.-P. (2011). "Whole genome sequence comparisons in taxonomy," in Methods in Microbiology. Taxonomy of Prokaryotes, eds F. Rainey and A. Oren (London: Academic Press), 409-436. doi: 10.1016/B978-0-12-387730-7.00018-8

Bushnell, B. (2020). BBMap Short Read Aligner, and Other Bioinformatic Tools. Available online at: https://sourceforge.net/projects/bbmap (accessed May 31, 2020).

Castillo, A. M., Gutiérrez, M. C., Kamekura, M., Xue, Y., Ma, Y., Cowan, D. A., et al. (2006). Natrinema ejinorense sp. nov., isolated from a saline lake in Inner Mongolia, China. Int. J. Syst. Evol. Microbiol. 56, 2683-2687. doi: 10.1099/ijs.0. 64421-0

Chen, S., Xu, Y., Sun, S., and Chen, F. (2019). Haloterrigena salifodinae sp. nov., an extremely halophilic archaeon isolated from a subterranean rock salt. Antonie van Leeuwenhoek 112, 1317-1329. doi: 10.1007/s10482-019-01264-w

Chun, J., and Rainey, F. A. (2014). Integrating genomics into the taxonomy and systematics of the Bacteria and Archaea. Int. J. Syst. Evol. Microbiol. 64, 316-324. doi: 10.1099/ijs.0.054171-0

Corral, P., de la Haba, R. R., Infante-Domínguez, C., Sánchez-Porro, C., Amoozegar, M. A., Papke, R. T., et al. (2018). Halorubrum chaoviator Mancinelli et al. 2009 is a later, heterotypic synonym of Halorubrum ezzemoulense Kharroub et al. 2006. Emended description of Halorubrum ezzemoulense Kharroub et al. 2006. Int. J. Syst. Evol. Microbiol. 68, 3657-3665. doi: 10.1099/ ijsem.0.003005

Cui, H.-L., Tohty, D., Zhou, P.-J., and Liu, S.-J. (2006b). Haloterrigena longa sp. nov. and Haloterrigena limicola sp. nov., extremely halophilic archaea isolated from a salt lake. Int. J. Syst. Evol. Microbiol. 56, 1837-1840. doi: 10.1099/ijs.0. 64372-0

Cui, H.-L., Tohty, D., Feng, J., Zhou, P.-J., and Liu, S.-J. (2006a). Natronorubrum aibiense sp. nov., an extremely halophilic archaeon isolated from Aibi salt lake in Xin-Jiang, China, and emended description of the genus Natronorubrum. Int. J. Syst. Evol. Microbiol. 56, 1515-1517. doi: 10.1099/ijs.0.64222-0

Cui, H.-L., Tohty, D., Liu, H.-C., Liu, S.-J., Oren, A., and Zhou, P.-J. (2007). Natronorubrum sulfidifaciens sp. nov., an extremely haloalkaliphilic archaeon isolated from Aiding salt lake in Xin-Jiang, China. Int. J. Syst. Evol. Microbiol. 57, 738-740. doi: 10.1099/ijs.0.64651-0

de la Haba, R. R., Corral, P., Sánchez-Porro, C., Infante-Domínguez, C., Makkay, A. M., Amoozegar, M. A., et al. (2018). Genotypic and lipid analyses of strains from the archaeal genus Halorubrum reveal insights into their taxonomy, divergence, and population structure. Front. Microbiol. 9:512. doi: 10.3389/ fmicb.2018.00512

de la Haba, R. R., López-Hermoso, C., Sánchez-Porro, C., Konstantinidis, K. T., and Ventosa, A. (2019). Comparative genomics and phylogenomic analysis of the genus Salinivibrio. Front. Microbiol. 10:2104. doi: 10.3389/fmicb.2019.02104

Deloger, M., El Karoui, M., and Petit, M.-A. (2009). A genomic distance based on MUM indicates discontinuity between most bacterial species and genera. J. Bacteriol. 191, 91-99. doi: 10.1128/JB.01202-08

Ding, J.-Y., Chen, S.-C., Lai, M.-C., and Liao, T.-L. (2017). Haloterrigena mahii sp. nov., an extremely halophilic archaeon from a solar saltern. Int. J. Syst. Evol. Microbiol. 67, 1333-1338. doi: 10.1099/ijsem.0.001811
Edgar, R. C. (2004). MUSCLE: multiple sequence alignment with high accuracy and high throughput. Nucleic Acids Res. 32, 1792-1797. doi: 10.1093/nar/gkh340

Enache, M., Itoh, T., Fukushima, T., Usami, R., Dumitru, L., and Kamekura, M. (2007). Phylogenetic relationships within the family Halobacteriaceae inferred from rpoB' gene and protein sequences. Int. J. Syst. Evol. Microbiol. 57, 22892295. doi: 10.1099/ijs.0.65190-0

Felsenstein, J. (1981). Evolutionary trees from DNA sequences: a maximum likelihood approach. J. Mol. Evol. 17, 368-376. doi: 10.1007/bf01734359

Felsenstein, J. (1985). Confidence limits on phylogenies: an approach using the bootstrap. Evolution 39, 783-791. doi: 10.1111/j.1558-5646.1985.tb00420.x

Fitch, W. M. (1971). Toward defining the course of evolution: minimum change for a specific tree topology. Syst. Biol. 20, 406-416. doi: 10.1093/sysbio/20.4.406

Flores, N., Hoyos, S., Venegas, M., Galetoviæ, A., Zúñiga, L. M., Fábrega, F., et al. (2020). Haloterrigena sp. strain SGH1, a bacterioruberin-rich, perchloratetolerant halophilic archaeon isolated from halite microbial communities, Atacama Desert, Chile. Front. Microbiol. 11:324. doi: 10.3389/fmicb.2020. 00324

Gaba, S., Kumari, A., Medema, M., and Kaushik, R. (2020). Pan-genome analysis and ancestral state reconstruction of class halobacteria: probability of a new super-order. Sci. Rep. 10:21205. doi: 10.1038/s41598-020-77723-6

Goris, J., Konstantinidis, K. T., Klappenbach, J. A., Coenye, T., Vandamme, P., and Tiedje, J. M. (2007). DNA-DNA hybridization values and their relationship to whole-genome sequence similarities. Int. J. Syst. Evol. Microbiol. 57, 81-91. doi: 10.1099/ijs.0.64483-0

Gupta, R. S., Naushad, S., Fabros, R., and Adeolu, M. (2016). A phylogenomic reappraisal of family-level divisions within the class Halobacteria: proposal to divide the order Halobacteriales into the families Halobacteriaceae, Haloarculaceae fam. nov., and Halococcaceae fam. nov., and the order Haloferacales into the families, Haloferacaceae and Halorubraceae fam. nov. Antonie van Leeuwenhoek 109, 565-587. doi: 10.1007/s10482-016-0660-2

Gutiérrez, M. C., Castillo, A. M., Corral, P., Minegishi, H., and Ventosa, A. (2010). Natronorubrum sediminis sp. nov., an archaeon isolated from a saline lake. Int. J. Syst. Evol. Microbiol. 60, 1802-1806. doi: 10.1099/ijs.0.015602-0

Gutiérrez, M. C., Castillo, A. M., Kamekura, M., and Ventosa, A. (2008). Haloterrigena salina sp. nov., an extremely halophilic archaeon isolated from a salt lake. Int. J. Syst. Evol. Microbiol. 58, 2880-2884. doi: 10.1099/ijs.0.2008/ 001602-0

Haft, D. H., DiCuccio, M., Badretdin, A., Brover, V., Chetvernin, V., O’Neill, K., et al. (2018). RefSeq: an update on prokaryotic genome annotation and curation. Nucleic Acids Res. 46, D851-D860. doi: 10.1093/nar/gkx1068

Infante-Domínguez, C., de la Haba, R. R., Corral, P., Sanchez-Porro, C., Arahal, D. R., and Ventosa, A. (2020). Genome-based analyses reveal a synonymy among Halorubrum distributum Zvyagintseva and Tarasov 1989; Oren and Ventosa 1996, Halorubrum terrestre Ventosa et al. 2004, Halorubrum arcis Xu et al. 2007 and Halorubrum litoreum Cui et al., 2007. Emended description of Halorubrum distributum Zvyagintseva and Tarasov 1989; Oren and Ventosa 1996. Int. J. Syst. Evol. Microbiol. 70, 1698-1705. doi: 10.1099/ijsem.0.00 3956

Jain, C., Rodriguez-R, L. M., Phillippy, A. M., Konstantinidis, K. T., and Aluru, S. (2018). High throughput ANI analysis of $90 \mathrm{~K}$ prokaryotic genomes reveals clear species boundaries. Nat. Commun. 9:5114. doi: 10.1038/s41467-018-07641-9

Jones, D. T., Taylor, W. R., and Thornton, J. M. (1992). The rapid generation of mutation data matrices from protein sequences. Comput. Appl. Biosci. 8, 275-282. doi: 10.1093/bioinformatics/8.3.275

Jukes, T. H., and Cantor, C. R. (1969). "Evolution of protein molecules," in Mammalian Protein Metabolism, Vol. III, ed. H. N. Munro (New York, NY: Academic Press), 21-132. doi: 10.1016/B978-1-4832-3211-9.50009-7

Kim, M., Oh, H.-S., Park, S.-C., and Chun, J. (2014). Towards a taxonomic coherence between average nucleotide identity and 16S rRNA gene sequence similarity for species demarcation of prokaryotes. Int. J. Syst. Evol. Microbiol. 64, 346-351. doi: 10.1099/ijs.0.059774-0

Kim, Y. B., Kim, J. Y., Song, H. S., Lee, C., Ahn, S. W., Lee, S. H., et al. (2018). Novel haloarchaeon Natrinema thermophila having the highest growth temperature among haloarchaea with a large genome size. Sci. Rep. 8:7777. doi: 10.1038/ s41598-018-25887-7

Konstantinidis, K. T., Rosselló-Móra, R., and Amann, R. (2017). Uncultivated microbes in need of their own taxonomy. ISME J. 11, 2399-2406. doi: 10.1038/ ismej.2017.113 
Konstantinidis, K. T., and Tiedje, J. M. (2005). Towards a genome-based taxonomy for prokaryotes. J. Bacteriol. 187, 6258-6264. doi: 10.1128/JB.187.18.6258-6264. 2005

Konstantinidis, K. T., and Tiedje, J. M. (2007). Prokaryotic taxonomy and phylogeny in the genomic era: advancements and challenges ahead. Curr. Opin. Microbiol. 10, 504-509. doi: 10.1016/j.mib.2007.08.006

Lee, I., Chalita, M., Ha, S.-M., Na, S.-I., Yoon, S.-H., and Chun, J. (2017). ContEst16S: an algorithm that identifies contaminated prokaryotic genomes using 16S RNA gene sequences. Int. J. Syst. Evol. Microbiol. 67, 2053-2057. doi: $10.1099 /$ ijsem. 0.001872

Lee, I., Kim, Y. O., Park, S. C., and Chun, J. (2016). OrthoANI: an improved algorithm and software for calculating average nucleotide identity. Int. J. Syst. Evol. Microbiol. 66, 1100-1103. doi: 10.1099/ijsem.0.000760

Letunic, I., and Bork, P. (2021). Interactive tree of life (iTOL) v5: an online tool for phylogenetic tree display and annotation. Nucleic Acids Res. 49, W293-W296. doi: 10.1093/nar/gkab301

Liu, D., Hunt, M., and Tsai, I. J. (2018). Inferring synteny between genome assemblies: a systematic evaluation. BMC Bioinformatics 19:26. doi: 10.1186/ s12859-018-2026-4

Mahansaria, R., Dhara, A., Saha, A., Haldar, S., and Mukherjee, J. (2018), Production enhancement and characterization of the polyhydroxyalkanoate produced by Natrinema ajinwuensis $($ as synonym) $=$ Natrinema altunense strain RM-G10. Int. J. Biol. Macromol. 107, 1480-1490. doi: 10.1016/j.ijbiomac.2017. 10.009

McGenity, T. J., Gemmell, R. T., and Grant, W. D. (1998). Proposal of a new halobacterial genus Natrinema gen. nov., with two species Natrinema pellirubrum nom. nov. and Natrinema pallidum nom. nov. Int. J. Syst. Bacteriol. 48, 1187-1196. doi: 10.1099/00207713-48-4-1187

Meier-Kolthoff, J. P., Auch, A. F., Klenk, H.-P., and Göker, M. (2013). Genome sequence-based species delimitation with confidence intervals and improved distance functions. BMC Bioinformatics 14:60. doi: 10.1186/1471-2105$14-60$

Minegishi, H., and Kamekura, M. (2019a). "Haloterrigena," in Bergey's Manual of Systematics of Archaea and Bacteria, eds W. B. Whitman, F. Rainey, P. Kämpfer, M. Trujillo, J. Chun, P. De Vos, et al. (Hoboken, NJ: John Wiley \& Sons, Inc., in association with Bergey's Manual Trust), 1-11. doi: 10.1002/9781118960608. gbm00488.pub2

Minegishi, H., and Kamekura, M. (2019b). "Natrinema," in Bergey's Manual of Systematics of Archaea and Bacteria, eds W. B. Whitman, F. Rainey, P. Kämpfer, M. Trujillo, J. Chun, P. De Vos, et al. (Hoboken, NJ: John Wiley \& Sons, Inc., in association with Bergey's Manual Trust), 1-11. doi: 10.1002/9781118960608. gbm00490.pub2

Minegishi, H., Kamekura, M., Itoh, T., Echigo, A., Usami, R., and Hashimoto, T. (2010). Further refinement of the phylogeny of the Halobacteriaceae based on the full-length RNA polymerase subunit B' ( $\left.r p o B^{\prime}\right)$ gene. Int. J. Syst. Evol. Microbiol. 60, 2398-2408. doi: 10.1099/ijs.0.017160-0

Minegishi, H., Shimogaki, R., Enomoto, S., Echigo, A., Kondo, Y., Nagaoka, S., et al. (2016). Halopiger thermotolerans sp. nov., a thermo-tolerant haloarchaeon isolated from commercial salt. Int. J. Syst. Evol. Microbiol. 66, 4975-4980. doi: 10.1099/ijsem.0.001455

Montalvo-Rodríguez, R., López-Garriga, J., Vreeland, R. H., Oren, A., Ventosa, A., and Kamekura, M. (2000). Haloterrigena thermotolerans sp. nov., a halophilic archaeon from Puerto Rico. Int. J. Syst. Evol. Microbiol. 50, 1065-1071. doi: 10.1099/00207713-50-3-1065

Oren, A., and Ventosa, A. (2002). International Committee on Systematics of Prokaryotes. Subcommittee on the taxonomy of Halobacteriaceae. Minutes of the meetings, 24 September 2001, Seville, Spain. Int. J. Syst. Evol. Microbiol. 52, 289-290. doi: 10.1099/00207713-52-1-289

Oren, A., Ventosa, A., and Kamekura, M. (2017). "Halobacteria," in Bergey's Manual of Systematics of Archaea and Bacteria, eds W. B. Whitman, F. Rainey, P. Kämpfer, M. Trujillo, J. Chun, P. De Vos, et al. (Hoboken, NJ: John Wiley \& Sons, Inc., in association with Bergey's Manual Trust), 1-5. doi: 10.1002/ 9781118960608.cbm00026.pub2

Palmer, M., Steenkamp, E. T., Blom, J., Hedlund, B. P., and Venter, S. N. (2020). All ANIs are not created equal: implications for prokaryotic species boundaries and integration of ANIs into polyphasic taxonomy. Int. J. Syst. Evol. Microbiol. 70, 2937-2948. doi: 10.1099/ijsem.0.004124
Papke, R. T. (2009). A critique of prokaryotic species concepts. Methods Mol. Biol. 532, 379-395. doi: 10.1007/978-1-60327-853-9_22

Papke, R. T., White, E., Reddy, P., Weigel, G., Kamekura, M., Minegishi, H., et al. (2011). A multilocus sequence analysis approach to the phylogeny and taxonomy of the Halobacteriales. Int. J. Syst. Evol. Microbiol. 61, 2984-2995. doi: 10.1099/ijs.0.029298-0

Parker, C. T., Tindall, B. J., and Garrity, G. M. (2019). International Code of Nomenclature of Prokaryotes. Int. J. Syst. Evol. Microbiol. 69, S1-S111. doi: 10.1099/ijsem.0.000778

Parte, A. C., Sardà Carbasse, J., Meier-Kolthoff, J. P., Reimer, L. C., and Göker, M. (2020). List of Prokaryotic names with Standing in Nomenclature (LPSN) moves to the DSMZ. Int. J. Syst. Evol. Microbiol. 70, 5607-5612. doi: 10.1099/ ijsem.0.004332

Post, F. J., and Al-Harjan, F. A. (1988). Surface activity of halobacteria and potential use in microbially enhanced oil recovery. Syst. Appl. Microbiol. 11, 97-101. doi: 10.1016/S0723-2020(88)80055-9

Price, M. N., Dehal, P. S., and Arkin, A. P. (2010). FastTree 2-approximately maximum-likelihood trees for large alignments. PLoS One 5:e9490. doi: 10. 1371/journal.pone.0009490

Qin, Q.-L., Xie, B.-B., Zhang, X.-Y., Chen, X.-L., Zhou, B.-C., Zhou, J., et al. (2014). A proposed genus boundary for the prokaryotes based on genomic insights. J. Bacteriol. 196, 2210-2215. doi: 10.1128/JB.01688-14

Ramírez-Durán, N., de la Haba, R. R., Vera-Gargallo, B., Sánchez-Porro, C., Alonso-Carmona, S., Sandoval-Trujillo, H., et al. (2020). Draft genome sequence of Saccharomonospora piscinae KCTC $19743^{\mathrm{T}}$, an actinobacterium containing secondary metabolite biosynthetic gene glusters. Microbiol. Resour. Announc. 9:e01588-19. doi: 10.1128/MRA.01588-19

Ramírez-Durán, N., de la Haba, R. R., Vera-Gargallo, B., Sánchez-Porro, C., Alonso-Carmona, S., Sandoval-Trujillo, H., et al. (2021). Taxogenomic and comparative genomic analysis of the genus Saccharomonospora focused on the identification of biosynthetic clusters PKS and NRPS. Front. Microbiol. 12:603791. doi: 10.3389/fmicb.2021.603791

Rasooli, M., Naghoni, A., Amoozegar, M. A., Mirfeizi, L., Moshtaghi Nikou, M., Shahzadeh Fazeli, S. A., et al. (2017). Natrinema soli sp. nov., a novel halophilic archaeon isolated from a hypersaline wetland. Int. J. Syst. Evol. Microbiol. 67, 2142-2147. doi: 10.1099/ijsem.0.001909

Richter, M., and Rossello-Mora, R. (2009). Shifting the genomic gold standard for the prokaryotic species definition. Proc. Natl. Acad. Sci. U.S.A. 106, 1912619131. doi: 10.1073/pnas. 0906412106

Rissman, A. I., Mau, B., Biehl, B. S., Darling, A. E., Glasner, J. D., and Perna, N. T. (2009). Reordering contigs of draft genomes using the Mauve aligner. Bioinformatics 25, 2071-2073. doi: 10.1093/bioinformatics/btp356

Rodriguez-R, L. M., and Konstantinidis, K. T. (2016). The enveomics collection: a toolbox for specialized analyses of microbial genomes and metagenomes. PeerJ Prepr. 4:e1900v1. doi: 10.7287/peerj.preprints.1900v1

Roh, S. W., Nam, Y.-D., Chang, H.-W., Kim, K.-H., Sung, Y., Kim, M.-S., et al. (2009). Haloterrigena jeotgali sp. nov., an extremely halophilic archaeon from salt-fermented food. Int. J. Syst. Evol. Microbiol. 59, 2359-2363. doi: 10.1099/ijs. $0.008243-0$

Romano, I., Poli, A., Finore, I., Huertas, F. J., Gambacorta, A., Pelliccione, S., et al. (2007). Haloterrigena hispanica sp. nov., an extremely halophilic archaeon from Fuente de Piedra, southern Spain. Int. J. Syst. Evol. Microbiol. 57, 1499-1503. doi: 10.1099/ijs.0.64895-0

Rosselló-Móra, R., and Amann, R. (2015). Past and future species definitions for Bacteria and Archaea. Syst. Appl. Microbiol. 38, 209-216. doi: 10.1016/j.syapm. 2015.02.001

Ruiz-Romero, E., Valenzuela-Encinas, C., López-Ramírez, M. P., de los Angeles Coutiño-Coutiño, M., Marsch, R., and Dendooven, L. (2013). Natronorubrum texcoconense sp. nov., a haloalkaliphilic archaeon isolated from soil of the former lake Texcoco (Mexico). Arch. Microbiol. 195, 145-151. doi: 10.1007/ s00203-012-0852-8

Saitou, N., and Nei, M. (1987). The neighbor-joining method: a new method for reconstructing phylogenetic trees. Mol. Biol. Evol. 4, 406-425. doi: 10.1093/ oxfordjournals.molbev.a040454

Shimodaira, H., and Hasegawa, M. (1999). Multiple comparisons of log-likelihoods with applications to phylogenetic inference. Mol. Biol. Evol. 16, 1114-1116. doi: 10.1093/oxfordjournals.molbev.a026201 
Sorokin, D. Y., Tourova, T. P., and Muyzer, G. (2005). Oxidation of thiosulfate to tetrathionate by an haloarchaeon isolated from hypersaline habitat. Extremophiles 9, 501-504. doi: 10.1007/s00792-005-0465-0

Sullivan, M. J., Petty, N. K., and Beatson, S. A. (2011). Easyfig: a genome comparison visualizer. Bioinformatics 27, 1009-1010. doi: 10.1093/bioinformatics/btr039

Tao, C.-Q., Ding, Y., Zhao, Y.-J., and Cui, H.-L. (2020). Natronorubrum halophilum sp. nov. isolated from two inland salt lakes. J. Microbiol. 58, 105-112. doi: 10.1007/s12275-020-9514-8

Tapingkae, W., Tanasupawat, S., Itoh, T., Parkin, K. L., Benjakul, S., Visessanguan, W., et al. (2008). Natrinema gari sp. nov., a halophilic archaeon isolated from fish sauce in Thailand. Int. J. Syst. Evol. Microbiol. 58, 2378-2383. doi: 10.1099/ ijs.0.65644-0

Tavaré, S. (1986). Some probabilistic and statistical problems in the analysis of DNA sequences. Lect. Math. Life Sci. 17, 57-86.

Tindall, B. J. (2003). Taxonomic problems arising in the genera Haloterrigena and Natrinema. Int. J. Syst. Evol. Microbiol. 53, 1697-1698. doi: 10.1099/ijs.0. 02529-0

Varghese, N. J., Mukherjee, S., Ivanova, N., Konstantinidis, K. T., Mavrommatis, K., Kyrpides, N. C., et al. (2015). Microbial species delineation using whole genome sequences. Nucleic Acids Res. 43, 6761-6771. doi: 10.1093/nar/ gkv657

Ventosa, A., Gutiérrez, M. C., Kamekura, M., and Dyall-Smith, M. L. (1999). Proposal to transfer Halococcus turkmenicus, Halobacterium trapanicum JCM 9743 and strain GSL-11 to Haloterrigena turkmenica gen. nov., comb. nov. Int. J. Syst. Bacteriol. 49, 131-136. doi: 10.1099/00207713-49-1-131

Wang, S., Yang, Q., Liu, Z.-H., Sun, L., Wei, D., Zhang, J.-Z., et al. (2010). Haloterrigena daqingensis sp. nov., an extremely haloalkaliphilic archaeon isolated from a saline-alkaline soil. Int. J. Syst. Evol. Microbiol. 60, 2267-2271. doi: 10.1099/ijs.0.013995-0

Westram, R., Bader, K., Prüsse, E., Kumar, Y., Meier, H., Glöckner, F. O., et al. (2011). "ARB: a software environment for sequence data," in Handbook of Molecular Microbial Ecology I: Metagenomics and Complementary Approaches, ed. F. J. de Bruijn (Hoboken, NJ: Wiley-Blackwell), 399-406. doi: 10.1002/ 9781118010518.ch46

Wright, A.-D. G. (2006). Phylogenetic relationships within the order Halobacteriales inferred from $16 \mathrm{~S}$ rRNA gene sequences. Int. J. Syst. Evol. Microbiol. 56, 1223-1227. doi: 10.1099/ijs.0.63776-0

Xin, H., Itoh, T., Zhou, P., Suzuki, K., Kamekura, M., and Nakase, T. (2000). Natrinema versiforme sp. nov., an extremely halophilic archaeon from Aibi salt lake, Xinjiang, China. Int. J. Syst. Evol. Microbiol. 50, 1297-1303. doi: 10.1099/ 00207713-50-3-1297

Xu, X.-W., Liu, S.-J., Tohty, D., Oren, A., Wu, M., and Zhou, P.-J. (2005a). Haloterrigena saccharevitans sp. nov., an extremely halophilic archaeon from
Xin-Jiang, China. Int. J. Syst. Evol. Microbiol. 55, 2539-2542. doi: 10.1099/ijs.0. 63761-0

Xu, X.-W., Ren, P.-G., Liu, S.-J., Wu, M., and Zhou, P.-J. (2005b). Natrinema altunense sp. nov., an extremely halophilic archaeon isolated from a salt lake in Altun Mountain in Xinjiang, China. Int. J. Syst. Evol. Microbiol. 55, 1311-1314. doi: 10.1099/ijs.0.63622-0

Xu, Y., Zhou, P., and Tian, X. (1999). Characterization of two novel haloalkaliphilic archaea Natronorubrum bangense gen. nov., sp. nov. and Natronorubrum tibetense gen. nov., sp. nov. Int. J. Syst. Bacteriol. 49, 261-266. doi: 10.1099/ 00207713-49-1-261

Yarza, P., Yilmaz, P., Pruesse, E., Glöckner, F. O., Ludwig, W., Schleifer, K.-H., et al. (2014). Uniting the classification of cultured and uncultured bacteria and archaea using 16S rRNA gene sequences. Nat. Rev. Microbiol. 12, 635-645. doi: $10.1038 /$ nrmicro3330

Yoon, S.-H., Ha, S.-M., Lim, J., Kwon, S., and Chun, J. (2017). A large-scale evaluation of algorithms to calculate average nucleotide identity. Antonie van Leeuwenhoek 110, 1281-1286. doi: 10.1007/s10482-017-0844-4

Zhang, W.-Y., Meng, Y., Zhu, X.-F., and Wu, M. (2013). Halopiger salifodinae sp. nov., an extremely halophilic archaeon isolated from a salt mine. Int. J. Syst. Evol. Microbiol. 63, 3563-3567. doi: 10.1099/ijs.0.050971-0

Zhang, Z., Liu, Y., Wang, S., Yang, D., Cheng, Y., Hu, J., et al. (2012). Temperate membrane-containing halophilic archaeal virus SNJ1 has a circular dsDNA genome identical to that of plasmid pHH205. Virology 434, 233-241. doi: 10. 1016/j.virol.2012.05.036

Zvyagintseva, I. S., and Tarasov, A. L. (1987). Extreme halophilic bacteria from saline soils. Mikrobiologiya 56, 839-844.

Conflict of Interest: The authors declare that the research was conducted in the absence of any commercial or financial relationships that could be construed as a potential conflict of interest.

Publisher's Note: All claims expressed in this article are solely those of the authors and do not necessarily represent those of their affiliated organizations, or those of the publisher, the editors and the reviewers. Any product that may be evaluated in this article, or claim that may be made by its manufacturer, is not guaranteed or endorsed by the publisher.

Copyright (c) 2021 de la Haba, Minegishi, Kamekura, Shimane and Ventosa. This is an open-access article distributed under the terms of the Creative Commons Attribution License (CC BY). The use, distribution or reproduction in other forums is permitted, provided the original author(s) and the copyright owner(s) are credited and that the original publication in this journal is cited, in accordance with accepted academic practice. No use, distribution or reproduction is permitted which does not comply with these terms. 